\title{
(2) OPEN ACCESS \\ British Society of Gastroenterology guidelines for the management of iron deficiency anaemia in adults
}

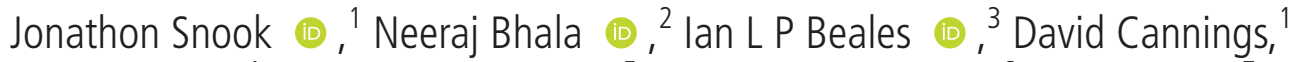 \\ Chris Kightley, ${ }^{4}$ Robert PH Logan $0{ }^{5},{ }^{5}$ D Mark Pritchard $(1),{ }^{6}$ Reena Sidhu, ${ }^{7}$ \\ Sue Surgenor, ${ }^{1}$ Wayne Thomas (i) , Ajay M Verma (1), ${ }^{4}$ Andrew F Goddard (i) ${ }^{9}$
}

${ }^{1}$ Gastroenterology, University Hospitals Dorset NHS Foundation Trust, Poole, UK ${ }^{2}$ Gastroenterology, Queen Elizabeth Hospital Birmingham, University Hospitals Birmingham NHS Foundation Trust and Institute of Applied Health Research, University of Birmingham, Birmingham, UK ${ }^{3}$ Gastroenterology, University of East Anglia, Norwich, UK ${ }^{4}$ Digestive Diseases, Kettering General Hospital NHS Foundation Trust, Kettering, UK ${ }^{5}$ Gastroenterology, Kings College Hospital, London, UK ${ }^{6}$ Institute of Systems, Molecular and Integrative Biology, University of Liverpool and Department of Gastroenterology, Liverpool University Hospitals NHS Foundation Trust, Liverpool, UK ${ }^{7}$ Gastroenterology, Royal Hallamshire Hospital, Sheffield, UK

${ }^{8}$ Haematology, Plymouth Hospitals NHS Foundation Trust, Plymouth, UK

${ }^{9}$ Gastroenterology, Royal Derby Hospital, Derby, UK

Correspondence to Dr Jonathon Snook, Gastroenterology, University Hospitals Dorset NHS Foundation Trust, Poole, Dorset, UK; jonathon.snook@gmail.com

JS and NB are joint first authors.

Received 19 May 2021

Accepted 26 July 2021

Published Online First

8 September 2021

Check for updates

(C) Author(s) (or their employer(s)) 2021. Re-use permitted under CC BY-NC. No commercial re-use. See rights and permissions. Published by BMJ.

To cite: Snook J, Bhala N, Beales ILP, et al. Gut

2021:70:2030-2051.

\section{ABSTRACT}

Iron deficiency anaemia (IDA) is a major cause of morbidity and burden of disease worldwide. It can generally be diagnosed by blood testing and remedied by iron replacement therapy (IRT) using the oral or intravenous route. The many causes of iron deficiency include poor dietary intake and malabsorption of dietary iron, as well as a number of significant gastrointestinal (GI) pathologies. Because blood is iron-rich it can result from chronic blood loss, and this is a common mechanism underlying the development of IDA—for example, as a consequence of menstrual or GI blood loss. Approximately a third of men and postmenopausal women presenting with IDA have an underlying pathological abnormality, most commonly in the GI tract. Therefore optimal management of IDA requires IRT in combination with appropriate investigation to establish the underlying cause. Unexplained IDA in all at-risk individuals is an accepted indication for fast-track secondary care referral in the UK because GI malignancies can present in this way, often in the absence of specific symptoms. Bidirectional GI endoscopy is the standard diagnostic approach to examination of the upper and lower GI tract, though radiological scanning is an alternative in some situations for assessing the large bowel. In recurrent or refractory IDA, wireless capsule endoscopy plays an important role in assessment of the small bowel.

IDA may present in primary care or across a range of specialties in secondary care, and because of this and the insidious nature of the condition it has not always been optimally managed despite the considerable burden of disease - with investigation sometimes being inappropriate, incorrectly timed or incomplete, and the role of IRT for symptom relief neglected. It is therefore important that contemporary guidelines for the management of IDA are available to all clinicians. This document is a revision of previous British Society of Gastroenterology guidelines, updated in the light of subsequent evidence and developments.

\section{EXECUTIVE SUMMARY OF RECOMMENDATIONS AND PRACTICE STATEMENTS \\ Background}

1. Iron deficiency anaemia (IDA) is common, and a major cause of morbidity worldwide (evidence quality-high, consensus-100\%, statement strength—strong).

2. IDA can be caused by a range of GI pathologies including cancer, and so GI investigation on an urgent basis should be considered in adults with a new diagnosis of IDA without obvious explanation (evidence quality_high, consensus- $85 \%$, statement strength-strong).

\section{Definitions}

3. We recommend that anaemia is defined as a haemoglobin $(\mathrm{Hb})$ concentration below the lower limit of normal for the relevant population and laboratory performing the test (evidence quality-medium, consensus-100\%, statement strength-strong).

4. We recommend that iron deficiency should be confirmed by iron studies prior to investigation. Serum ferritin is the single most useful marker of IDA, but other blood tests (eg, transferrin saturation) can be helpful if a false-normal ferritin is suspected (evidence quality-medium, consensus-92\%, statement strength—strong).

5. We recommend that a good response to iron therapy ( $\mathrm{Hb}$ rise $\geq 10 \mathrm{~g} / \mathrm{L}$ within a 2-week timeframe) in anaemic patients is highly suggestive of absolute iron deficiency, even if the results of iron studies are equivocal (evidence quality —-medium, consensus-100\%, statement strength—strong).

\section{Initial clinical assessment}

6. We recommend taking a detailed history, as it may provide important clues as to the cause(s) of IDA in the individual case (evidence quality-low, consensus-100\%, statement strength-strong).

7. We recommend that initial investigation of confirmed IDA should include urinalysis or urine microscopy, screening for coeliac disease (CD) and in appropriate cases, endoscopic examination of the upper and lower GI tract (evidence quality - moderate, consensus - $85 \%$, statement strength—strong).

8. $\mathrm{CD}$ is found in $3 \%-5 \%$ of cases of IDA, and we recommend that it should be routinely screened for serologically, or on small bowel biopsy at the time of gastroscopy (evidence quality — high, consensus - $84 \%$, statement strength-strong).

9. Age, sex, $\mathrm{Hb}$ concentration and mean cell volume are all independent predictors of risk of GI cancer in IDA, and need to be considered as part of a holistic risk assessment. It follows that the cancer risk in iron deficiency without anaemia is low (evidence quality — high, consensus-92\%, statement strength—strong). 
10. There are insufficient grounds at present to recommend faecal immunochemical testing for risk stratification in patients with IDA. The evidence base is evolving rapidly, however, and on that basis, this guidance may therefore change (evidence quality-low, consensus-100\%, statement strength-weak).

11. We recommend that in men and postmenopausal women with newly diagnosed IDA, gastroscopy and colonoscopy should generally be the first-line GI investigations. In those not suitable for colonoscopy, CT colonography is a reasonable alternative (evidence quality-moderate, consensus-100\%, statement strength—strong).

\section{Follow-up and recurrent IDA}

12. Hb levels normalise with iron replacement therapy (IRT) in most cases of IDA, but IDA recurs in a minority of these on long-term follow-up (evidence quality-low, consensus-92\%, statement strength—strong).

\section{Further evaluation of the small bowel}

13. In those with negative bidirectional endoscopy of acceptable quality and either an inadequate response to IRT or recurrent IDA, we recommend further investigation of the small bowel and renal tract to exclude other causes (evidence quality-moderate, consensus-85\%, statement strength-strong).

14. We recommend capsule endoscopy as the preferred test for examining the small bowel in IDA because it is highly sensitive for mucosal lesions. CT/MR enterography may be considered in those not suitable, and these are complementary investigations in the assessment of inflammatory and neoplastic disease of the small bowel (evidence qualityhigh, consensus-100\%, statement strength-strong).

15. After a negative capsule endoscopy of acceptable quality, we recommend that further GI investigation needs to be considered only if there is ongoing IDA after IRT (evidence qualityhigh, consensus-100\%, recommendation-strong).

16. We recommend that long-term IRT may be an appropriate strategy when the cause of recurrent IDA is unknown or irreversible (evidence quality-low, consensus-100\%, statement strength—strong).

\section{Treatment of IDA}

17. We recommend that IRT should not be deferred while awaiting investigations for IDA unless colonoscopy is imminent (evidence quality — high, consensus-100\%, statement strength-strong).

18. We recommend that the initial treatment of IDA should be with one tablet per day of ferrous sulphate, fumarate or gluconate. If not tolerated, a reduced dose of one tablet every other day, alternative oral preparations or parenteral iron should be considered (evidence quality-medium, consensus-92\%, statement strength-strong).

19. Limited transfusion of packed red cells may on occasion be required to treat symptomatic IDA, in which case IRT is still necessary post-transfusion (evidence quality—high, consensus-100\%, statement strength-strong).

20. We recommend that patients should be monitored in the first 4 weeks for an $\mathrm{Hb}$ response to oral iron, and treatment should be continued for a period of around 3 months after normalisation of the $\mathrm{Hb}$ level, to ensure adequate repletion of the marrow iron stores (evidence quality-medium, consensus-92\%, statement strength—strong).
21. We recommend that parenteral iron should be considered when oral iron is contraindicated, ineffective or not tolerated. This consideration should be at any early stage if oral IRT is judged unlikely to be effective (see the Treatment section), and/or the correction of IDA is particularly urgent (evidence quality — high, consensus—92\%, statement strength-strong).

22. There is insufficient evidence to support invasive investigation in non-anaemic iron deficiency unless there are additional indications (see the Definitions section), but periodic blood count monitoring is suggested (evidence quality-low, consensus-92\%, statement strength-weak).

23. After the restoration of $\mathrm{Hb}$ and iron stores with IRT, we recommend that the blood count should be monitored periodically (perhaps every 6 months initially) to detect recurrent IDA (evidence quality-very low, consensus- $85 \%$, statement strength—strong).

\section{Special situations-young women}

24. IDA is common in young women, and major contributory factors include menstrual losses, pregnancy and poor dietary intake (evidence quality—high, consensus-100\%, statement strength-strong).

25. Underlying GI pathology is uncommon in young women with IDA, and so after screening for CD, we recommend that further investigation is warranted only if there are additional clinical features of concern-as detailed in the text (evidence quality - moderate, consensus-92\%, statement strength-strong).

26. If GI investigation in a pregnant woman is deemed necessary prior to delivery, gastroscopy and (after the first trimester) MR enterography are considered safe in pregnancy (evidence quality-low, consensus-91\%, statement strength-strong).

\section{Special situations-young men}

27. Confirmed IDA is uncommon in young men, but when found we recommend that it warrants the same investigational algorithm as for older people (evidence quality — moderate, consensus-100\%, statement strength-strong).

\section{Special situations-the elderly}

28. Iron deficiency is common in the elderly, and is often multifactorial in aetiology (evidence quality-high, consensus - $100 \%$, statement strength—strong).

29. We recommend that the risks and benefits of invasive endoscopic and alternative investigation(s) are carefully considered in those with major comorbidities and/or limited performance status (evidence quality-medium, consensus-92\%, statement strength—strong).

\section{Special situations-specific comorbidities}

30. Functional iron deficiency (FID) is a common contributory factor to the anaemia associated with advanced chronic kidney disease (CKD) (evidence quality—high, consensus-92\%, statement strength-strong).

31. Iron deficiency is common in chronic heart failure (CHF), and is often multifactorial (evidence quality-high, consensus-92\%, statement strength—strong).

32. Parenteral IRT may improve symptoms and quality of life in CHF with FID (evidence quality-moderate, consensus-100\%, statement strength—strong). 
33. In the management of iron deficiency associated with CKD or CHF, reference to the appropriate specialist published guidelines is recommended (evidence quality-moderate, consensus-92\%, statement strength—strong).

34. IDA is a common manifestation of IBD, particularly when the disease is active (evidence quality - high, consensus-100\%, statement strength-strong).

35. Intolerance and malabsorption of oral IRT can be particular problems in the treatment of IBD-associated IDA, and parenteral IRT may be required (evidence quality—medium, consensus-100\%, statement strength—strong).

\section{Special situations-GI surgery}

36. IDA is common following resection or bypass surgery involving the stomach and/or small bowel, including bariatric surgery (evidence quality-high, consensus-92\%, statement strength-strong).

37. In new presentations of IDA, we recommend that a history of GI or bariatric surgery should not preclude a search for other causes of IDA (evidence quality-low, consensus-85\%, statement strength—strong).

\section{Service considerations}

38. We recommend that all service providers should have clear points of referral and management pathways for patients with IDA (evidence quality-low, consensus-100\%, statement strength-strong).

39. To ensure efficient use of resources, we recommend that IDA pathways should be delivered by a designated team led by a senior clinician (evidence quality-low, consensus-100\%, statement strength—strong).

40. We recommend that service providers should aim to have an ambulatory care base for the administration of parenteral iron (evidence quality-low, consensus-100\%, statement strength-strong).

\section{BACKGROUND}

1. Iron deficiency anaemia (IDA) is common, and a major cause of morbidity worldwide (evidence quality-high, consensus-100\%, statement strength-strong).

2. IDA can be caused by a range of GI pathologies including cancer, and so GI investigation on an urgent basis should be considered in adults with a new diagnosis of IDA without obvious explanation (evidence quality-high, consensus- $85 \%$, statement strength-strong).

Anaemia affects about a third of the global population and is a major cause of morbidity worldwide. ${ }^{12}$ Iron deficiency is one of the dominant causes, and the resulting anaemia (iron deficiency anaemia (IDA)) has a point prevalence of $2 \%-5 \%$ among adult men and postmenopausal women in the developed world. ${ }^{3-5}$

IDA is the most common form of anaemia seen in primary care in the UK. It is estimated to account for more than 57000 emergency admissions to UK hospitals each year, costing the National Health Service (NHS) more than $£ 55$ million per annum. ${ }^{6}$

While menstrual loss is commonly the cause of IDA in premenopausal women, IDA in adult men and postmenopausal women is often due to chronic blood loss from the GI tract. $^{45-12}$ IDA may be the first presenting manifestation of colonic or oesophago-gastric carcinoma, highlighting the importance of swift and complete investigation. There are however many other recognised causes of IDA (table 1) including malabsorption (most commonly from coeliac disease (CD) in the UK), poor dietary intake, blood donation, gastrectomy and use of
Table 1 Pathological disorders associated with iron deficiency anaemia

\begin{tabular}{|c|c|}
\hline \multicolumn{2}{|l|}{ Chronic blood loss } \\
\hline \multirow[t]{4}{*}{ Digestive tract } & $\begin{array}{l}\text { Neoplastic—most commonly colonic } \\
\text { adenocarcinoma }\end{array}$ \\
\hline & $\begin{array}{l}\text { Inflammatory-for example, peptic ulceration, } \\
\text { IBD }\end{array}$ \\
\hline & Vascular malformations_-angiodysplasia \\
\hline & Parasitic_for example, hookworm \\
\hline Genito-urinary tract & $\begin{array}{l}\text { Haematuria, pathological gynaecological } \\
\text { bleeding—all causes, including malignancy }\end{array}$ \\
\hline Respiratory tract & Recurrent epistaxis, haemoptysis—all causes \\
\hline \multicolumn{2}{|l|}{ Malabsorption syndromes } \\
\hline \multirow[t]{4}{*}{ Hypochlorhydria } & Atrophic gastritis \\
\hline & Helicobacter pylori infection \\
\hline & Gastrectomy/gastric bypass \\
\hline & Proton-pump inhibitors \\
\hline Iron chelation & $\begin{array}{l}\text { Tea, coffee, calcium, flavonoids, oxalates, phytates } \\
\text { Wide range of antacids, Pica syndrome }\end{array}$ \\
\hline \multirow[t]{4}{*}{ Enteropathies } & Coeliac disease \\
\hline & Crohn's disease \\
\hline & NSAID enteropathy \\
\hline & $\begin{array}{l}\text { Rarer enteropathies, for example, Whipple's } \\
\text { disease, bacterial overgrowth }\end{array}$ \\
\hline Small bowel surgery & Small bowel resection/bypass \\
\hline \multirow[t]{2}{*}{ Genetic disorders } & Iron-refractory iron deficiency anaemia \\
\hline & Divalent metal transporter 1 deficiency anaemia \\
\hline \multicolumn{2}{|c|}{ Associated with the anaemia of chronic disease } \\
\hline \multicolumn{2}{|l|}{ Chronic heart failure } \\
\hline \multicolumn{2}{|l|}{ Chronic kidney disease } \\
\hline Chronic inflammatory disorders & $\begin{array}{l}\text { For example rheumatoid arthritis, inflammatory } \\
\text { bowel disease }\end{array}$ \\
\hline
\end{tabular}

NSAID, non-steroidal anti-inflammatory drug.

non-steroidal anti-inflammatory drugs (NSAIDs). IDA is often multifactorial, and dual pathology (ie, significant disease in both upper and lower GI tract) is found in 1\%-10\% of cases-this should be particularly considered in the older patient. ${ }^{45-12}$

IDA may present in primary care, or across a range of specialties in secondary care, and historically the management of IDA was often suboptimal-with investigation being slow, inadequate or incomplete. ${ }^{13-15}$ Over recent years, however, the recognition that IDA may reflect serious underlying GI pathology has resulted in increasing involvement of gastroenterology services. IDA may now account for $10 \%$ or more of all gastroenterology referrals, and a typical district hospital unit in the UK with a catchment of 250000 may have in excess of 400 IDA referrals per annum. ${ }^{16} 17$

\section{SCOPE}

The objective of these guidelines is to summarise contemporary evidence on the diagnosis and management of IDA in adults, and to provide recommendations based on this in the light of developments since the original publication in 2000, last updated in $2011 .^{18}$ The guidelines are primarily intended for health professionals in primary and secondary care in the UK, though many aspects are relevant to health services elsewhere in the world.

\section{METHOD}

These guidelines were commissioned by the British Society of Gastroenterology (BSG) in 2018, following a proposal approved by the Clinical Standards and Services Committee. They were 
developed in accordance with the BSG guideline process (revised version 2018) and the Agree II instrument. ${ }^{19} 20$

A committee of 13 members was convened from interested individuals representing a range of disciplines including gastroenterology, haematology, specialist nursing and patient groups, under the co-chairmanship of AFG and NB. Two lay members on the Guideline Committee represented patients and the general public. Following discussion of the scope and purpose of the guidelines and the key issues, a formal literature search was undertaken by the National Guidelines Centre using all subcategories of the term "iron deficiency anaemia". Leads were identified to oversee the writing of section drafts based on a review of the relevant literature, and to produce draft sets of recommendations relevant to each section: Definitions-WT; Initial assessment-JS; Coeliac disease and further evaluation-RS; Treatment-ILPB; Special situations-MP, NB, AFG; Service considerations-RL. JS led on collating the consensus statements and editing the section drafts into a unified guideline document.

These recommendations were subject to three rounds of anonymised consensus voting by the full committee in an eDelphi exercise during 2020 using an online platform (ECD Solutions, Columbus, USA). Recommendations were modified in the light of feedback from previous rounds, and those reaching a consensus of over $80 \%$ were incorporated into the final document.

For each statement, section leads provided a grading of the quality of the supporting evidence, and the strength of the recommendation-these assessments were all ratified by the co-chairs. The quality of the supporting evidence was semiquantified using the GRADE system (high, moderate, low, very low). ${ }^{21}$ The recommendation strength (strong, weak) was based on the evidence quality, but as in many cases this was low or very low, a range of other factors were considered including (as appropriate) the degree of consensus, the perceived risk/benefit balance, patient views, resource costs and expert opinion.

Information regarding evidence quality, eDelphi consensus and recommendation strength is summarised for each statement in the executive summary. The final document was read and approved by all members of the guideline committee, and formally assessed and approved by the Clinical Services and Standards Committee of the BSG.

\section{DEFINITIONS}

3. We recommend that anaemia is defined as a haemoglobin $(\mathrm{Hb})$ concentration below the lower limit of normal for the relevant population and laboratory performing the test (evidence quality-medium, consensus-100\%, statement strength—strong).

4. We recommend that iron deficiency should be confirmed by iron studies prior to investigation. Serum ferritin is the single most useful marker of IDA, but other blood tests (eg, transferrin saturation) can be helpful if a false-normal ferritin is suspected (evidence quality-medium, consensus-92\%, statement strength—strong).

5. We recommend that a good response to iron therapy $(\mathrm{Hb}$ rise $\geq 10 \mathrm{~g} / \mathrm{L}$ within a 2 -week timeframe) in anaemic patients is highly suggestive of absolute iron deficiency, even if the results of iron studies are equivocal (evidence quality-medium, consensus-100\%, statement strength—strong).

\section{Anaemia}

The WHO defines anaemia as a haemoglobin $(\mathrm{Hb})$ concentration below $130 \mathrm{~g} / \mathrm{L}$ in men over 15 years of age, below $120 \mathrm{~g} / \mathrm{L}$ in non-pregnant women over 15 years of age and below $110 \mathrm{~g} / \mathrm{L}$ in pregnant women in the second and third trimester. ${ }^{22}$ The diagnostic criteria for anaemia in IDA vary between published studies. $^{7-12}$ The normal range for $\mathrm{Hb}$ also varies between different populations in the UK. It is reasonable to use the lower limit of the normal range for the laboratory performing the test to define anaemia, but these should be aligned with the WHO defined lower limits. ${ }^{2}$

There is little consensus as to the level of anaemia that requires investigation. The National Institute for Health and Care Excellence (NICE) referral guidelines in the UK for suspected lower GI cancer suggest that IDA with an Hb concentration $<110 \mathrm{~g} / \mathrm{L}$ in men or $<100 \mathrm{~g} / \mathrm{L}$ in non-menstruating women warrants fast-track referral. ${ }^{23}$ These cut-off values will however miss some cases of colorectal cancer, especially in men. ${ }^{24} 25$ It is therefore advised that investigation should be considered at any level of anaemia in the presence of iron deficiency, though the case is stronger in those with more severe degrees of anaemia, as they are more likely to have serious underlying GI pathology. ${ }^{112425}$

\section{Iron deficiency}

Automated cell counters provide measurements of the changes in red cells that accompany iron deficiency including reduced mean cell $\mathrm{Hb}(\mathrm{MCH})$-hypochromia; and reduced mean cell volume (MCV)-microcytosis. ${ }^{26} \mathrm{MCH}$ is probably a more reliable marker of iron deficiency as it is less dependent on storage and the counting machine used, and a reduction is seen in both absolute and functional iron deficiency (FID). $\mathrm{MCH}$ may also be more sensitive for iron deficiency than $\mathrm{MCV}^{27}$ Both microcytosis and hypochromia lose sensitivity for iron deficiency in the presence of chronic disease, thalassaemia or vitamin B12/folate deficiency. ${ }^{28}$

The specificity of $\mathrm{MCV}$ and $\mathrm{MCH}$ for iron deficiency is limited, as microcytosis and hypochromia also occur in many haemoglobinopathies (such as thalassaemia, when the MCV is typically reduced out of proportion to the level of anaemia), in sideroblastic anaemia and in some cases of anaemia of chronic disease. To prevent unnecessary GI investigation, Hb electrophoresis is recommended in those with microcytosis and normal iron studies, particularly if there is an appropriate ethnic background.

The serum markers of iron deficiency include low ferritin, low transferrin saturation, low iron, raised total iron-binding capacity, raised red cell zinc protoporphyrin, increased serum transferrin receptor (sTfR), low reticulocyte $\mathrm{Hb}$ (Retic-Hb) and raised percentage hypochromic red cells. Serum ferritin (SF) is the most specific test for iron deficiency in the absence of inflammation. An SF level of $<15 \mu \mathrm{g} / \mathrm{L}$ is indicative of absent iron stores, while SF levels of less than $30 \mu \mathrm{g} / \mathrm{L}$ are generally indicative of low body iron stores. The lower limit of normal for most laboratories, therefore, lies in the range $15-30 \mu \mathrm{g} / \mathrm{L}^{29-31}$

As SF is an acute phase protein, however, apparently normal levels may occur with iron deficiency in the context of an inflammatory disease process. ${ }^{26}$ An SF cut-off of $45 \mu \mathrm{g} / \mathrm{L}$ has been suggested as providing the optimal trade-off between sensitivity and specificity for iron deficiency in practice. ${ }^{32}$ An SF value above $150 \mu \mathrm{g} / \mathrm{L}$ is unlikely to occur with absolute iron deficiency, even in the presence of inflammation. ${ }^{33}$

In summary, an SF $<15 \mu \mathrm{g} / \mathrm{L}$ is highly specific for iron deficiency (specificity 0.99). A cut-off of $45 \mu \mathrm{g} / \mathrm{L}$ provides a respectable specificity of 0.92 , and figures below this may warrant consideration of GI investigation, especially in the context of a chronic inflammatory process with anaemia. 
The sTfR concentration is a good marker of iron deficiency in otherwise healthy subjects, ${ }^{34}$ but it can also be raised where there is increased erythropoietic drive such as with haemolytic anaemias, thalassaemias and $\mathrm{Hb} \mathrm{E}^{29}$ —and most UK hospitals do not provide this test. The $\left[\mathrm{sTfR} / \log _{10}\right.$ ferritin] ratio may provide superior discrimination to either test on its own, particularly in chronic disease. ${ }^{35}$

A therapeutic trial of oral iron replacement therapy (IRT) for 2-4 weeks may aid with the diagnosis of IDA, but is dependent on compliance. $\mathrm{A} \geq 10 \mathrm{~g} / \mathrm{L}$ rise in $\mathrm{Hb}$ over a 2 -week period is highly sensitive for absolute iron deficiency. ${ }^{36}$ While further tests to confirm iron deficiency are occasionally necessary, estimation of iron concentration in bone marrow is invasive, often subjective and difficult to justify in most cases.

After excluding thalassaemia carriage, low Retic-Hb provides evidence of iron restriction, and should be considered in the laboratory work-up of anaemia particularly where there is chronic renal impairment. ${ }^{37}$ Retic-Hb is reported to be a more reliable marker of iron restriction than sTfR in healthy blood donors. ${ }^{38}$ An early indicator of response to iron therapy in IDA is provided by a rising Retic-Hb on day $4,{ }^{39}$ similar to the observation of a falling percentage of hypochromic red cells in response to therapy. ${ }^{40}$ An algorithm for the diagnostic approach to IDA is suggested in figure 1 .

\section{Functional iron deficiency}

Absolute iron deficiency describes a situation where body iron stores are inadequate to meet demands, while in FID the supply of iron for erythropoiesis is inadequate despite apparently normal iron stores in cells of the monocyte-macrophage system. This restrictive effect is modulated by hepcidin, which also limits iron absorption through the gut mucosa.

A common clinical setting for FID is CKD, where parenteral iron therapy facilitates the response to administered erythropoietin to correct anaemia. FID is also one element of the anaemia of chronic disease, occurring in many chronic inflammatory conditions such as rheumatoid arthritis and IBD. A detailed discussion of the complex pathogenesis of the anaemia of chronic disease is beyond the scope of these guidelines.

An area of difficulty is establishing whether patients with presumed FID (with raised inflammatory markers and an SF in the normal range) have reduced iron stores indicative of absolute deficiency. When attributing anaemia to FID, it is important to consider whether there is sufficient evidence of a chronic illness. Evidence from studies in CKD suggests that in the absence of thalassaemia, the percentage of hypochromic red cells and Retic- $\mathrm{Hb}$ are superior to transferrin saturation in predicting the response to intravenous iron therapy. ${ }^{41} \mathrm{~A}$ transferrin saturation of $<20 \%$ is indicative of iron restriction, particularly in thalassaemia carriers. ${ }^{41}$

Similar evidence that low Retic-Hb is an independent marker of iron restriction in the non-CKD setting, ${ }^{42-44}$ and for example provides a reliable marker of iron stores in patients with IBD. ${ }^{45} \mathrm{~A}$ very low hepcidin level is more commonly seen in absolute than FID, and may therefore indicate the probability of a response to oral IRT, ${ }^{46}$ but few UK laboratories offer this test. A good haematological response to a trial of oral iron suggests absolute iron deficiency rather than FID.

Given that chronic inflammatory conditions are common and that SF values may therefore be difficult to interpret, it is important to use additional clinical and laboratory information when considering whether further GI investigations are warranted. Clinical features (eg, bowel-related symptoms), inflammatory markers (eg C-reactive protein (CRP)), transferrin saturation, red cell hypochromia and response to oral IRT can all be helpful in this complex clinical setting.

\section{Non-anaemic iron deficiency}

The development of anaemia from iron deficiency goes through an initial phase where body iron stores are depleted resulting in hypoferritinaemia, but the $\mathrm{Hb}$ concentration is still within the normal range (non-anaemic iron deficiency (NAID)). For example, in a study of young women with menorrhagia, over half had reduced iron stores but only $25 \%$ were actually anaemic. ${ }^{47}$

The overall prevalence of significant underlying GI pathology, and in particular of GI malignancy, is low in NAID. ${ }^{25}$ In the absence of other pointers, GI investigation generally is not warranted in premenopausal women since the cause is likely to be menstrual blood loss and/or recent pregnancy (see the Special situations section). The threshold for investigation of NAID should however be low in men, postmenopausal women, and those with GI symptoms or a family history of GI pathology.

\section{INITIAL CLINICAL ASSESSMENT}

6. We recommend taking a detailed history, as it may provide important clues as to the cause(s) of IDA in the individual case (evidence quality-low, consensus-100\%, statement strength-strong).

7. We recommend that initial investigation of confirmed IDA should include urinalysis or urine microscopy, screening for coeliac disease (CD) and in appropriate cases, endoscopic examination of the upper and lower GI tract (evidence quality-moderate, consensus- $85 \%$, statement strength—strong).

8. CD is found in 3\%-5\% of cases of IDA, and we recommend that it should be routinely screened for serologically, or on small bowel biopsy at the time of gastroscopy (evidence quality-high, consensus- $84 \%$, statement strength—strong).

9. Age, sex, $\mathrm{Hb}$ concentration and mean cell volume are all independent predictors of risk of GI cancer in IDA, and need to be considered as part of a holistic risk assessment. It follows that the cancer risk in iron deficiency without anaemia is low (evidence quality-bigh, consensus-92\%, statement strength-strong).

10. There are insufficient grounds at present to recommend faecal immunochemical testing for risk stratification in patients with IDA. The evidence base is evolving rapidly, however, and on that basis, this guidance may therefore change. (evidence quality-low, consensus-100\%, statement strength-weak).

11. We recommend that in men and postmenopausal women with newly diagnosed IDA, gastroscopy and colonoscopy should generally be the first-line GI investigations. In those not suitable for colonoscopy, CT colonography is a reasonable alternative (evidence quality-moderate, consensus-100\%, statement strength-strong).

\section{Service provision}

IDA is a common clinical problem with fairly clear diagnostic criteria, a degree of case homogeneity, and straightforward algorithms for treatment and investigation. ${ }^{48}$ These features make the condition eminently suitable for streamlined management in dedicated nurse-led IDA clinics, as have been developed in a number of units around the UK. ${ }^{4-51}$ An algorithm for the management approach to IDA is suggested in figure 2 .

\section{History and examination}

Clinical assessment of a subject with IDA may reveal manifestations of anaemia (eg, breathlessness, fatigue, heart failure) 


\section{Anaemia possibly due to iron deficiency}
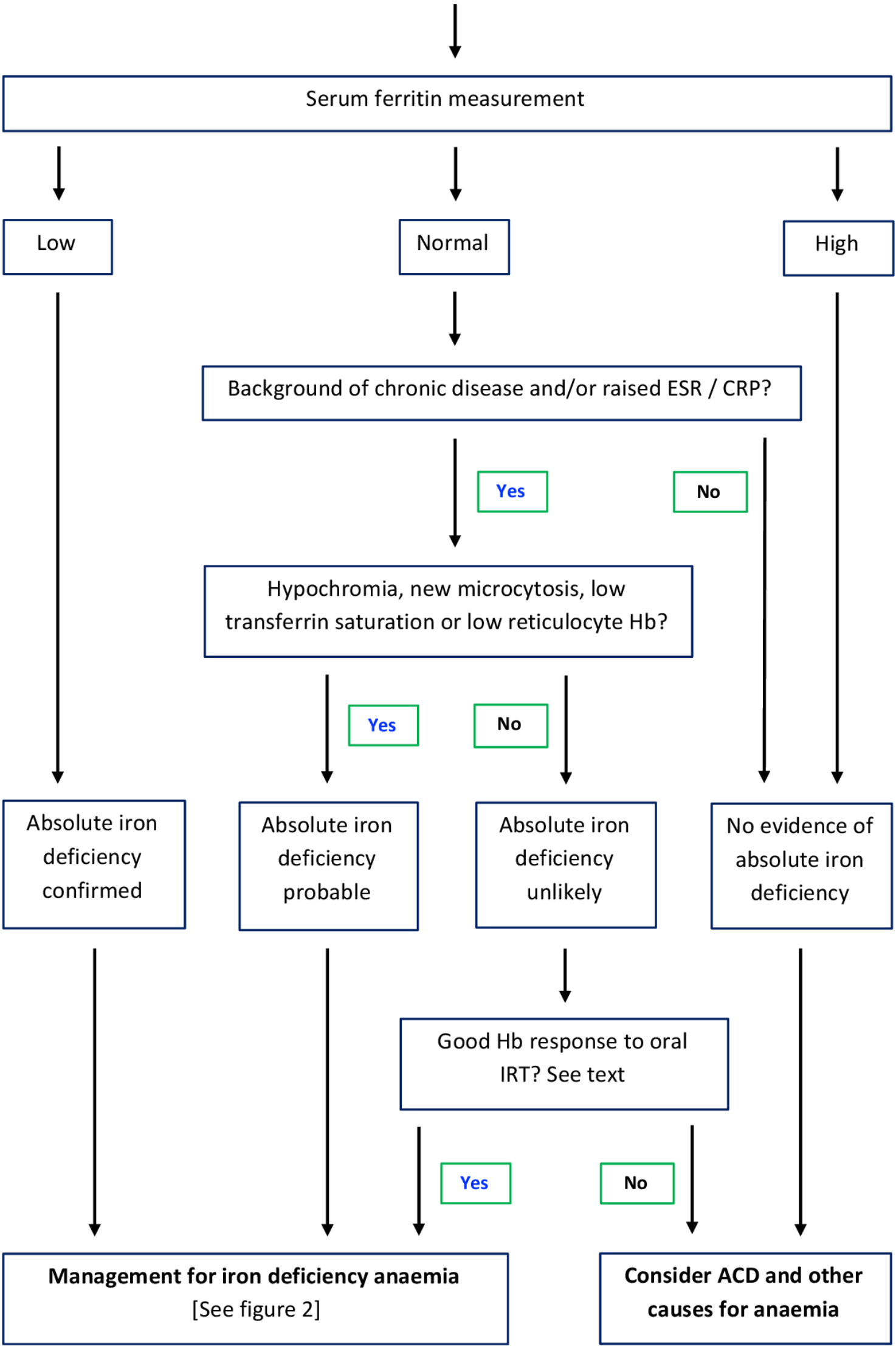

Figure 1 Algorithm for the diagnosis of iron deficiency anaemia. ACD, anaemia of chronic disease; CRP, C-reactive protein; ESR, erythrocyte sedimentation rate; $\mathrm{Hb}$, haemoglobin; IRT, iron replacement therapy. 


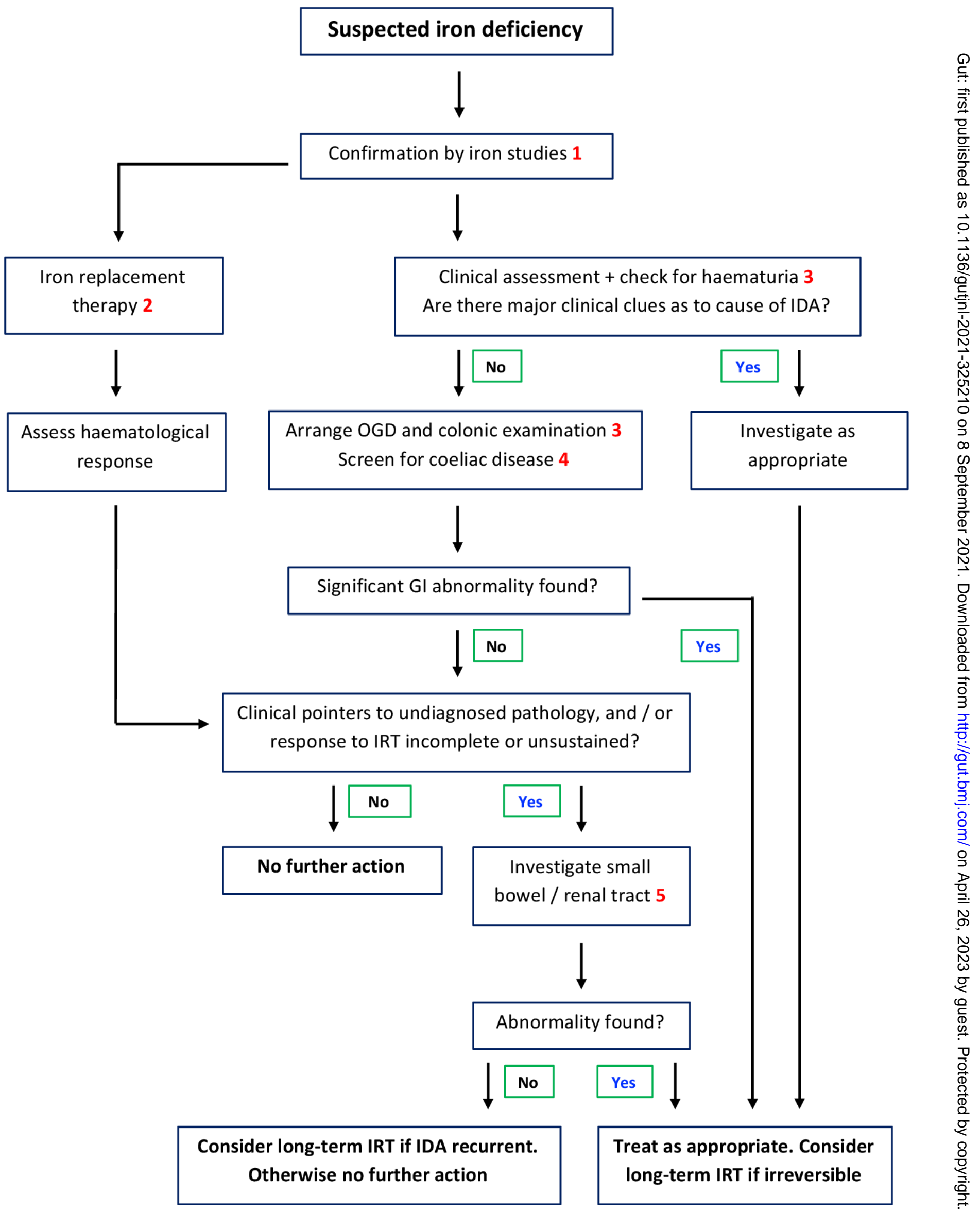

Figure 2 Algorithm for the management of IDA. Section reference key: 1—diagnosis, 2-treatment, 3—clinical assessment, 4-coeliac disease, 5-further evaluation. IDA, iron deficiency anaemia; IRT, iron replacement therapy; OGD, oesophago-gastroduodenoscopy. 
and on occasion more specifically of iron deficiency (such as angular stomatitis, glossitis, koilonychia, restless legs syndrome, pagophagia (a craving for ice), blue sclerae). A personal or family background of GI disease may provide a clue as to the cause of IDA. A family history of true iron-refractory IDA is rare, but if given may suggest a genetic disturbance of the pathway controlling iron absorption. ${ }^{52}$

Even if present, abdominal symptoms are not a reliable guide to the presence, nature or location of underlying GI pathology. ${ }^{16}$ Physical examination is generally unremarkable, but may on occasion provide the diagnosis, for example, in hereditary haemorrhagic telangiectasia.

There are many potential contributors to a negative iron balance, leading to IDA (see table 1). Particular risk factors that should be sought include chronic overt blood loss (eg, nosebleeds, menstruation), blood donation, inadequate dietary intake, longterm NSAID usage and previous resectional or bypass surgery of the GI tract. More recently it has been recognised that long-term proton pump inhibitor(PPI) therapy may contribute to the risk of iron deficiency, ${ }^{53}$ presumably as a result of impaired absorption secondary to hypochlorhydria, and that IDA is common in endurance athletes-the mechanism is uncertain, but high hepcidin levels may contribute. ${ }^{54}$ Iron deficiency is however often multifactorial, and so the presence of one or more of these risk factors should not necessarily be a deterrent to further GI investigation, particularly in older age groups.

\section{Preliminary investigations}

CD is a relatively common cause of IDA ${ }^{175556}$ and should be routinely excluded in all age groups (see the later section). Renal tract pathology, in particular renal cell carcinoma, ${ }^{57}$ is a wellrecognised though uncommon cause of IDA due to chronic blood loss, and so all subjects presenting with unexplained IDA should at least be checked for microscopic haematuria. Urine dipstick testing and mid-stream urine (MSU) analysis have limited sensitivity and specificity for renal tract pathology, but nevertheless, after exclusion of infection, a persisting positive result is an indication for urological investigation.

\section{Imaging of the GI tract \\ How to investigate}

Standard practice is to examine the upper and lower GI tracts at gastroscopy and colonoscopy respectively, and many units undertake both procedures at the same session. ${ }^{10} 1732$ This approach is more efficient than separate procedures and, given the patient is already prepared, simplifies the decision to proceed to colonoscopy if there are abnormalities of uncertain relevance to IDA in the upper GI tract. Given that most series have revealed some cases with dual unrelated pathology, the recommendation is to defer colonoscopy only if an upper GI cancer is found. Overall, investigation of the GI tract in IDA reveals potentially significant pathology in about a third of cases ${ }^{16} 1758$-there is a myriad of recognised GI causes, as outlined in table 1.

CT colonography is an acceptable alternative to colonoscopy, ${ }^{59}{ }^{60}$ and may be preferable in certain clinical situations, such as in the presence of major comorbidities. The advantage of CT colonography is that it is less invasive, does not require sedation and provides limited imaging of the other viscera. The disadvantage is that it does not identify more subtle mucosal pathology such as vascular malformations, and there may be some circumstances where a colonoscopy is subsequently required to obtain histology, remove a polyp, or insert a tattoo prior to laparoscopic resection.
There is a limited place for contrast CT without bowel preparation in those with IDA and major comorbidities including frailty, accepting that this will only identify relatively gross pathology, and will miss some cancers. The value of investigating those where the outcome is unlikely to affect management does however need to be carefully considered (see the Special situations section). There is no longer a role for contrast fluoroscopy in the investigation of the upper and lower GI tract in IDA.

Atrophic gastritis is a recognised contributor to the development of IDA, probably because of the impairment of iron absorption that accompanies all causes of achlorhydria. ${ }^{5}$ In support of this, subgroup analysis of a small study has suggested that atrophic gastritis may be commoner in those without a definite alternative explanation for IDA than in those with ${ }^{61} \mathrm{Helico}-$ bacter infection has also been weakly associated with the risk of developing IDA ${ }^{62}$ though it is unclear whether this reflects the effect of related pathologies such as peptic ulceration or atrophic gastritis. The same meta-analysis suggested that Helicobacter eradication does not improve the $\mathrm{Hb}$ response to IRT. ${ }^{62} \mathrm{It}$, therefore, remains to be established whether the cost of routine gastric biopsies in IDA is justified, given that the results are unlikely to directly alter management. ${ }^{32}$

\section{Who to investigate}

The investigation of IDA potentially involves a considerable workload with a relatively low yield, and so there is a strong case for targeting valuable investigational resources. Cancer is by far the most serious pathology underlying IDA, but even following previous guidelines advising investigation of males and postmenopausal women, cancer is only found in $8 \%-10 \%$ of cases $^{11} 1758$ - and the majority of investigations reveal no other significant abnormalities either.

It is also important to bear in mind that premenopausal women do on occasion develop cancer in the GI tract, and that cancer is not the only GI pathology underlying IDA. There is therefore sometimes justification for investigating younger women-particularly if the IDA is severe or recurrent, and disproportionate to perceived menstrual losses (see the Special situations section).

There is now evidence that individuals with IDA can be stratified for the risk of underlying GI cancer based on a set of simple and objective clinical variables-specifically age, sex, MCV and $\mathrm{Hb}$ concentration. ${ }^{1125}$ The IDIOM App ${ }^{63}$ has been developed to provide a swift estimate of GI cancer risk in IDA, which may help inform the patient discussion as to the potential benefit of investigation. Further refinement of the risk stratification process with the incorporation of additional clinical variables may allow the identification of sizeable subgroups who can safely avoid invasive procedures altogether. ${ }^{25}$

\section{Role of faecal immunochemical testing}

The introduction of faecal immunochemical testing (FIT) for trace quantities of blood in the stool has provided a major step forward in risk stratification for those presenting with clinical features that are potentially due to colorectal cancer (CRC), and the value of it has been demonstrated in a series of large observational studies. ${ }^{64-69}$ FIT is currently recommended by NICE for determining whether IDA in the under-60 age group warrants fast-track referral ${ }^{23}$-while this suggestion is logical, the evidence base is limited.

The place of FIT in risk stratification for the IDA population as a whole-either as a stand-alone or in conjunction with established tools-remains to be established. There are reasons 
Table 2 Summary of recent real-world studies of the performance of quantitative FIT in the prediction of colorectal cancer (CRC) in adults with clinical pointers to this diagnosis, showing data for FIT-negative cancers with IDA (reference 68 assessed all-cause anaemia rather than confirmed IDA)

\begin{tabular}{|c|c|c|c|c|c|}
\hline \multirow[b]{2}{*}{ Reference } & \multicolumn{2}{|c|}{ Number of subjects } & \multirow[b]{2}{*}{$\begin{array}{l}\text { Sensitivity of } \\
\text { FIT for CRC }\end{array}$} & \multicolumn{2}{|c|}{ FIT-negative CRCs } \\
\hline & Screened & CRC found & & Total & $\begin{array}{l}\text { No with } \\
\text { IDA }\end{array}$ \\
\hline Chapman et $\mathrm{al}^{64}$ & 795 & 40 & $87.5 \%$ & 5 & 5 \\
\hline Mowat et al ${ }^{65}$ & 1447 & 95 & $87.4 \%$ & 12 & 7 \\
\hline Nicholson et al ${ }^{66}$ & 9896 & 105 & $90.5 \%$ & 12 & 4 \\
\hline$D^{\prime}$ Souza et al ${ }^{67}$ & 9822 & 329 & $90.9 \%$ & 30 & 4 \\
\hline Lazlo et al ${ }^{68}$ & 3596 & 90 & $83.3 \%$ & 15 & 8 \\
\hline Cunin et $\mathrm{al}^{69}$ & 1000 & 48 & $85.4 \%$ & 7 & 4 \\
\hline Total & 26556 & 707 & & 81 & 32 \\
\hline
\end{tabular}

Data for an arbitrary detection threshold of $10 \mu \mathrm{g} / \mathrm{g}$ is shown for direct comparison.

FIT, faecal immunochemical testing; IDA, iron deficiency anaemia.

for caution about a FIT-based triage system for IDA. First, CRC accounts for only a minority of the pathology found on the investigation of IDA, particularly in those under 60. Second, data from six recently published studies of real-world experience confirm that even at the low detection threshold of $10 \mu \mathrm{g} / \mathrm{g}$, the sensitivity of FIT for CRC ranges from $83 \%$ to $91 \%{ }^{64-69}$ Furthermore, although numbers are small, there is the suspicion that IDA may be over-represented in the FIT negative CRC subgroup, accounting for $32(40 \%)$ of the 81 pooled cases. The data are summarised in table 2 . This conclusion is supported by a meta-analysis of the few IDA-specific studies in the published literature, which yielded a sensitivity of $83 \%$ of FIT for CRC, with concerns that this may be an over-estimate due to publication bias. $^{70}$

Currently therefore we are unable to advocate the use of FIT for risk stratification or colorectal cancer exclusion in IDA, though this view may change with the appearance of a stronger evidence base. While it seems logical to consider the result of FIT in the overall assessment of the risk serious organic disease, safety netting is still required to ensure that serious pathology is not missed. BSG guidance will be updated as further evidence for the role of FIT in IDA is evaluated, and a BSG Association of Coloproctology of Great Britain and Ireland (ACPGBI) guidelines group has recently been commissioned to assess this.

\section{COELIAC DISEASE AND IDA}

$\mathrm{CD}$ is found in $3 \%-5 \%$ of subjects investigated for unexplained IDA as demonstrated by studies from the UK, Europe, USA and Middle East. ${ }^{1755}$ Duodenal biopsy histology remains the gold standard for exclusion or confirmation of the diagnosis. Coeliac serology - anti-tissue transglutaminase (tTG) or antiendomysial antibody-is however a useful screening test. ${ }^{327172}$ A prospective study of 2000 referrals for gastroscopy (all indications including anaemia, mean age 56 years) with parallel serology and histology yielded both a sensitivity and a specificity of tTG IgA antibody for CD of $90.9 \%$, with a negative predictive value of $99.6 \% .^{73}$

With emerging evidence on the reliability of serology with an anti-tTG IgA titre of greater than $10 \times$ the upper limit of normal, ${ }^{74}$ the BSG has issued interim guidance on a "no biopsy' protocol in patients under the age of 50 years during the COVID-19 pandemic, provided they have no alarm symptoms. An updated guideline on the diagnosis of CD in adults is expected in 2022.

Retrospective studies suggest that antibody-negative CD accounts for about $2 \%$ of the total coeliac population, ${ }^{75} 76$ though this may be an under-estimate due to ascertainment bias (seronegative subjects are less likely to get a biopsy), and the true figure may be nearer $10 \% .^{5673}$ As standard serological screening tests are IgA-based, apparently seronegative CD can result from IgA deficiency. This only accounts for a minority of antibodynegative cases however, ${ }^{5671}$ and screening for it may not be costeffective as the result only marginally changes the probability of CD.

As the relative prevalence of seronegative $\mathrm{CD}$ is highest in the elderly, ${ }^{567577}$ the sensitivity of coeliac serology for CD falls with age. This has importance in the investigation of IDA, where the incidence is highest in the elderly, and the median age at presentation is over $70 .{ }^{17}$ As the sensitivity of serology for CD can be as low as $74 \%$ in coeliacs presenting with IDA, ${ }^{56}$ it may be that an age-related approach to investigation is most appropriate.

In a younger patient with IDA, where the sensitivity of serology for CD is high and the risk of other serious pathology low, a check on coeliac serology may be all that is required, with gastroscopy and biopsy only if the result is positive. Other factors of course may influence the need for further investigation-colonoscopy, for example, should be considered in those with a strong family history of colorectal cancer.

In an older subject with IDA, the sensitivity of serology for CD is rather lower, while the probability of other pathology and in particular GI malignancy, is much higher, and dual pathology is more common. ${ }^{17}$ So a more appropriate approach in this situation might be bidirectional endoscopy (BDE) with duodenal biopsy to exclude CD.

Presentation of CD in later life is well recognised, ${ }^{5678-81}$ and indeed the seroprevalence of undiagnosed CD is similar to that in younger age-groups. ${ }^{82} \mathrm{CD}$ in the elderly may however be more likely to present with manifestations of malabsorption, including IDA. ${ }^{787981}$ There is conflicting evidence as to whether a diagnosis of $\mathrm{CD}$ over the age of 50 confers an increased cancer risk relative to the general population of the same age,${ }^{83}$ but the possibility of a concurrent GI neoplasm should always be considered. Older patients with CD and IDA and any patient with alarm features should be considered for BDE, but no specific age or Hb cut-off can be recommended due to lack of published evidence.

\section{FOLLOW-UP AND RECURRENT IDA}

12. Hb levels normalise with iron replacement therapy (IRT) in most cases of IDA, but IDA recurs in a minority of these on long-term follow-up (evidence quality-low, consensus- $92 \%$, statement strength-strong).

16. We recommend that long-term IRT may be an appropriate strategy when the cause of recurrent IDA is unknown or irreversible (evidence quality_low, consensus-100\%, statement strength-strong).

23. After the restoration of $\mathrm{Hb}$ and iron stores with IRT, we recommend that the blood count should be monitored periodically (perhaps every 6 months initially) to detect recurrent IDA (evidence quality-very low, consensus-85\%, statement strength-strong).

IDA should be treated with IRT as detailed in the Treatment section, and if the initial investigation reveals the cause, it should obviously be addressed as appropriate. However, the majority of individuals presenting with unexplained IDA will have negative BDE, no evidence of $\mathrm{CD}$, no other symptoms, and a complete and sustained haematological response to IRT. In this situation, the outlook is generally favourable, ${ }^{425185-88}$ and there is no need for further investigation other than a periodic blood count after completion of IRT to check for recurrent IDA. In an era of 
limited resources, we would suggest checks at perhaps 3, 6, 12 and 24 months.

Further investigation is however warranted if there is any evidence of active undiagnosed pathology. Pointers to this possibility include symptoms such as ongoing weight loss or chronic unexplained diarrhoea, persistently elevated inflammatory markers and the persistence or recurrence of IDA. Persistent IDA describes the situation where there is haematological evidence of ongoing iron deficiency despite adequate IRT, while in recurrent IDA the haematological abnormalities resulting from iron deficiency resolve with IRT, only to reappear at a later date.

Depending on the circumstances, further investigation may involve repeat $\mathrm{BDE}$, particularly if the original procedures were felt to have provided inadequate views or to be outdated. Detailed imaging of the small bowel is an important element of further assessment (see the Small bowel section). Finally, formal imaging of the renal tract should be considered regardless of the result of testing for microscopic haematuria, in view of the recognised association of renal cell carcinoma with IDA. ${ }^{57}$

Depending on the definition employed, IDA proves to be recurrent in the medium term in $12 \%-25 \%$ of cases following previous negative BDE and a complete response to IRT. ${ }^{17} 88$ Recurrent IDA will respond in most cases respond to further IRT.

There are no established algorithms for the investigation of recurrent IDA, but our recommendation is to follow the principles outlined earlier. In particular, repeat BDE is advised if the previous investigations are outdated. There is no validated definition of this, but a threshold of 2 years has been suggested on the basis of limited evidence. ${ }^{17}$

The diagnostic yield of small bowel examination by capsule endoscopy (CE) is high in recurrent IDA unexplained by adequate imaging of the upper and lower GI tract (see the Small bowel section). The most common findings are vascular malformations (sometimes single but more commonly multiple) and Crohn's disease, though tumours account for a small percentage of cases. ${ }^{1789}$

The prevalence depends on definitions, but in a significant minority of cases of recurrent IDA, no convincing cause is found despite comprehensive investigation of the GI and renal tracts. Long-term IRT is an appropriate management strategy when the cause of recurrent IDA is unknown or where it is irreversible, for example, secondary to atrophic gastritis or previous GI surgery.

\section{FURTHER EVALUATION OF THE SMALL BOWEL}

13. In those with negative bidirectional endoscopy of acceptable quality and either an inadequate response to IRT or recurrent IDA, we recommend further investigation of the small bowel and renal tract to exclude other causes (evidence quality-moderate, consensus-85\%, statement strength-strong).

14. We recommend capsule endoscopy as the preferred test for examining the small bowel in IDA because it is highly sensitive for mucosal lesions. CT/MR enterography may be considered in those not suitable, and these are complementary investigations in the assessment of inflammatory and neoplastic disease of the small bowel (evidence quality - high, consensus-100\%, statement strength—strong).

15. After a negative capsule endoscopy of acceptable quality, we recommend that further GI investigation needs to be considered only if there is ongoing IDA after IRT (evidence quality-high, consensus- $100 \%$, statement strength—strong).

$\mathrm{CE}$ is now the first-line test for assessment of the small bowel in the setting of covert bleeding/IDA, as it has a higher diagnostic yield than radiology. ${ }^{90-92}$ A pooled diagnostic yield of
$66.6 \%$ (95\% CI $61 \%$ to $72 \%$ ) has been reported in a systematic review of CE in IDA. ${ }^{93}$ Angioectasia, Crohn's disease and NSAID enteropathy are common findings, ${ }^{1789}$ 94-96 and factors such as transfusion dependence, increasing age and comorbidity all positively influence the diagnostic yield. ${ }^{97} \mathrm{~A}$ longer small bowel transit time on CE is also associated with a higher yield, ${ }^{96}{ }^{98}$ so the possibility of missed pathology should be considered when transit is unduly rapid.

The pathology found on CE is actually within reach of standard gastroscopy in up to $28 \%$ of cases. ${ }^{99} 100$ Such lesions include in particular Cameron's ulcers, gastric antral vascular ectasia and vascular anomalies high on the lesser curve. Repeating gastroscopy prior to CE in all patients is not cost-effective, ${ }^{101} 102$ but should be considered on an individual case basis, particularly if views were previously poor or there has been a major time lapse since the last gastroscopy. Similarly, lesions may be missed in the right colon, particularly in the elderly and when preparation has been suboptimal. ${ }^{97} 102$

While the pick-up rate for small bowel pathology is significantly higher in the elderly, there is emerging evidence of the value of $\mathrm{CE}$ in younger age groups with IDA, though with differences in aetiology. ${ }^{89} 103$ A retrospective European cooperative study of 220 cases under the age of 50 revealed significant pathology in $32 \%$, neoplastic in $5 \% .{ }^{104}$ On multivariate analysis, a low MCV and weight loss were independent predictors of significant pathology. ${ }^{104}$

The rebleeding potential is low following a negative $\mathrm{CE}$, and a conservative approach can in general be followed. ${ }^{105} \mathrm{CE}$ does however have a miss rate, importantly for small bowel tumours. ${ }^{106}$ Indications warranting additional investigation after a negative CE may include a further $\mathrm{Hb}$ drop of $>40 \mathrm{~g} / \mathrm{L}$, and a change in presentation from occult to overt bleeding. ${ }^{105}$ In the context of suspected small bowel bleeding including IDA, there is limited evidence to support repeating CE after an initial negative study in cases where there remains a strong suspicion of undiagnosed pathology, with a yield of up to $45 \%$. $^{107} 108$

Device-assisted enteroscopy (DAE), an endoscopic technique that allows deep intubation of the small bowel, provides the option for endoscopic biopsy and/or therapy, but this is an invasive procedure, and the need for it should be directed by the findings on CE. Predictably, the diagnostic yield of doubleballoon enteroscopy is significantly higher if preceded by a positive CE than a negative one. ${ }^{109}$

Vascular lesions (angioectasia) are a common finding on CE, particularly in the elderly, and cohort studies have demonstrated that endoscopic ablation may reduce rebleeding rates and transfusion requirements. ${ }^{110} 111$ There are however no randomised controlled trials, and a systematic review has suggested that the rebleeding rate after ablation of small bowel angioectasia is not dissimilar to that of historical (untreated) controls. ${ }^{112}$ As angioectasia is a benign condition, conservative management with longterm IRT is therefore a reasonable alternative-particularly in the context of non-intrusive IDA and/or significant comorbidity.

The majority of small bowel lesions underlying IDA are subtle vascular or inflammatory abnormalities, undetectable by conventional radiology. CT enterography (CTE) does however have a role in delineating small bowel tumours seen on $\mathrm{CE}$, and the combination of arterial venous and phases is helpful in characterising vascular small bowel tumours and detecting metastases. In addition of course, CTE may reveal evidence of other neoplasia underlying IDA, such as lymphoma or tumours of the renal tract.

Most series in the published literature on studies comparing CTE and small bowel endoscopy have combined cases of IDA 
and overt small bowel bleeding. Meta-analyses have concluded that CTE and CE/DAE are best considered complementary investigations. ${ }^{113} 114$ CTE may have a higher yield for tumours, although this is a tentative conclusion due to small numbers. ${ }^{115}$

\section{TREATMENT OF IDA}

17. We recommend that IRT should not be deferred while awaiting investigations for IDA unless colonoscopy is imminent (evidence quality-high, consensus-100\%, statement strength—strong).

18. We recommend that the initial treatment of IDA should be with one tablet per day of ferrous sulphate, fumarate or gluconate. If not tolerated, a reduced dose of one tablet every other day, alternative oral preparations or parenteral iron should be considered (evidence quality-medium, consensus-92\%, statement strength—strong).

19. Limited transfusion of packed red cells may on occasion be required to treat symptomatic IDA, in which case IRT is still necessary post-transfusion (evidence quality-high, consensus-100\%, statement strength—strong).

20. We recommend that patients should be monitored in the first 4 weeks for an $\mathrm{Hb}$ response to oral iron, and treatment should be continued for a period of around 3 months after normalisation of the $\mathrm{Hb}$ level, to ensure adequate repletion of the marrow iron stores (evidence quality-medium, consensus-92\%, statement strength—strong).

21. We recommend that parenteral iron should be considered when oral iron is contraindicated, ineffective or not tolerated. This consideration should be at any early stage if oral IRT is judged unlikely to be effective (see text), and/or the correction of IDA is particularly urgent (evidence quality-high, consensus-92\%, statement strength-strong).

22. There is insufficient evidence to support invasive investigation in non-anaemic iron deficiency unless there are additional indications (see text), but periodic blood count monitoring is suggested (evidence quality-low, consensus-92\%, statement strength-weak).

23. After the restoration of $\mathrm{Hb}$ and iron stores with IRT, we recommend that the blood count should be monitored periodically (perhaps every 6 months initially) to detect recurrent IDA (evidence quality-very low, consensus-85\%, statement strength-strong).

The treatment of iron deficiency aims to (i) restore normal circulating $\mathrm{Hb}$ levels, (ii) replenish body iron stores, (iii) improve quality of life and (iv) improve physiological function. Successful IRT should achieve all of these outcomes. ${ }^{36} 116-118$ An algorithm providing an overview of the treatment of IDA is shown in figure 3, and the elements of this are discussed in more detail below.

\section{Oral IRT}

It is usual to start treatment for IDA as soon as the diagnosis has been confirmed by laboratory investigation, so that the treatment and investigation of IDA proceed in parallel. There is usually a beneficial rise in $\mathrm{Hb}$ within 2 weeks of commencing oral IRT. ${ }^{36}$ Oral iron preparations often stain the stools and may cause constipation, so it is usual practice to pause these prior to bowel preparation for colonoscopy. Therefore, if a patient is to be investigated for IDA within 2 weeks, it would be appropriate to delay treatment until after the colonoscopy has been completed. There is no need to withhold oral iron before gastroscopy or CT colonography.
Traditionally oral iron salts were taken as split dose, two or three times a day. More recent data suggest that lower doses and more infrequent administration may be just as effective, while probably associated with lower rates of adverse effects. In addition, it may be inconvenient for some people to find three periods during the day to take iron on an empty stomach.

Various oral iron preparations are available in the UK (table 3). Traditional oral iron salts (ferrous sulfate, ferrous gluconate and ferrous fumarate) are inexpensive, effective, safe and readily available-and they remain the standard therapies for IDA. Their use is supported by considerable clinical experience and observational data. In a pooled analysis of trial data, $72.8 \%$ of patients with IDA demonstrated a satisfactory response to an oral iron formulation, defined as an $\mathrm{Hb}$ rise of $>10 \mathrm{~g} / \mathrm{L}$ within 2 weeks, though rates of normalisation of $\mathrm{Hb}$ were lower with continued bleeding or clinically evident GI disease. ${ }^{36}$

A Cochrane analysis in 2014 highlighted that the reviewed trials were of poor quality, but concluded that in comparison to placebo oral IRT significantly improves $\mathrm{Hb}$ levels in IDA, and probably reduces blood transfusion requirements. ${ }^{119}$ When given in standard doses there do not appear to be important differences in efficacy or adverse events, ${ }^{119}$ although side effects may be lower with less than daily dosing. ${ }^{120}$ Modified release preparations (table 3 ) release iron in the more distal small bowel beyond the areas of most active assimilation-they do not enhance iron absorption ${ }^{121} 122$ or reduce side effects, ${ }^{123}$ and their use is not recommended.

The absorption of oral iron salts is significantly impaired if taken with food. Taking iron with meals can reduce bioavailability by up to $75 \% .^{124}$ This necessitates iron being taken either in the fasting state first thing in the morning or in periods between meals during the day. It is not clear how soon after oral iron food can be taken, but the inhibitory effect of tea on iron absorption dissipates within $60 \mathrm{~min} .{ }^{125}$ Despite previous suggestions of benefit, ${ }^{121}$ coadministration of vitamin $\mathrm{C}$ with oral IRT is not recommended-a recent large randomised controlled trial has confirmed that it neither enhances the haematological response or rate of iron loading, nor diminishes side effects. ${ }^{126}$

Iron absorption from oral preparations is determined by a complex interplay involving total body iron stores, erythropoietic activity of the bone marrow, recent exposure of the small intestine to iron and systemic inflammation. ${ }^{35}{ }^{127-131}$ Hepcidin is the most important inhibitor of iron absorption. Hepcidin levels follow a diurnal pattern and increase after oral iron intake, impairing fractional absorption of subsequent doses. ${ }^{131} 132$

Short-term studies of iron-depleted but otherwise healthy women have shown that oral doses of $60 \mathrm{mg}$ elemental iron stimulate increased hepcidin levels for the next 24 hours, thus reducing subsequent iron absorption by $35 \%-45 \%{ }^{131}$ As a consequence, the overall absorption of iron from $60 \mathrm{mg}$ of elemental iron taken once a day was similar to that from 60 mg two times a day. Therapy with low dose oral iron has been reported to be successful and safe in elderly patients with IDA-a daily dose of $15 \mathrm{mg}$ of elemental iron was as effective as $50 \mathrm{mg}$ or $150 \mathrm{mg}$ in terms of the $\mathrm{Hb}$ response, with a lower incidence of adverse effects. ${ }^{133}$

There are limited data on outcomes at lower dosage frequencies. Alternate day dosing leads to a significantly increased fractional iron and total iron absorption in iron-depleted healthy women. ${ }^{132134}$ Fractional iron absorption was significantly higher with alternate day administration of $100 \mathrm{mg}$ or $200 \mathrm{mg}$ elemental iron compared with daily dosing. ${ }^{134}$ Importantly, the overall iron absorption from $200 \mathrm{mg}$ on alternate days was almost twice that from the equivalent dosage of $100 \mathrm{mg}$ on consecutive days. ${ }^{134} \mathrm{In}$ 


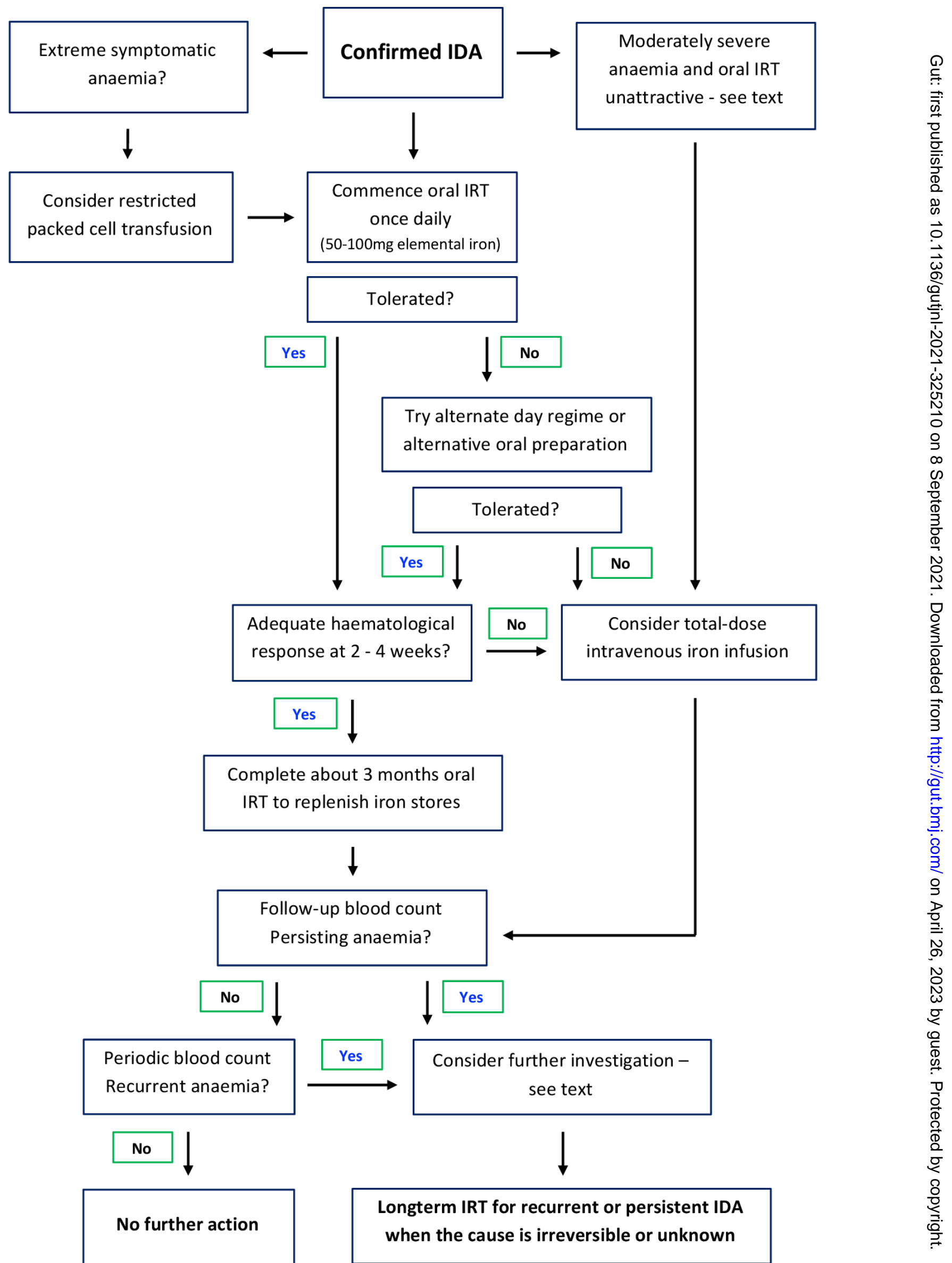

Figure 3 Overview of treatment algorithm for IDA. IDA, iron deficiency anaemia; IRT, iron replacement therapy. 
Table 3 A comparison of oral iron preparations available in the UK (February 2021)

\begin{tabular}{|c|c|c|c|c|}
\hline Formulation & Preparation & Dose & Elemental iron & $\operatorname{Cost} / \mp^{*}$ \\
\hline \multirow[t]{4}{*}{ Ferrous sulfate } & Tablet & $200 \mathrm{mg}$ & $65 \mathrm{mg}$ & $1.00 \dagger$ \\
\hline & Drops & $125 \mathrm{mg} / \mathrm{mL}$ & $25 \mathrm{mg} / \mathrm{mL}$ & 60.00 \\
\hline & MR tabletł & $325 \mathrm{mg}$ & $105 \mathrm{mg}$ & 2.58 \\
\hline & MR capsuleł & $150 \mathrm{mg}$ & $48 \mathrm{mg}$ & 3.95 \\
\hline $\begin{array}{l}\text { Ferrous sulfate } \\
\text { with ascorbic acid }\end{array}$ & MR tabletł & $325 \mathrm{mg}$ & $105 \mathrm{mg}$ & 3.20 \\
\hline $\begin{array}{l}\text { Ferrous sulfate } \\
\text { with folic acid }\end{array}$ & MR tabletł & $325 \mathrm{mg}$ & $105 \mathrm{mg}$ & 2.64 \\
\hline Ferrous gluconate & Tablet & $300 \mathrm{mg}$ & $37 \mathrm{mg}$ & 2.18 \\
\hline \multirow[t]{4}{*}{ Ferrous fumarate } & Tablet & $210 \mathrm{mg}$ & $69 \mathrm{mg}$ & 1.33 \\
\hline & Capsule & $305 \mathrm{mg}$ & $100 \mathrm{mg}$ & 1.40 \\
\hline & Tablet & $322 \mathrm{mg}$ & $106 \mathrm{mg}$ & 1.00 \\
\hline & Liquid & $140 \mathrm{mg} / 5 \mathrm{~mL}$ & $45 \mathrm{mg} / 5 \mathrm{~mL}$ & 4.00 \\
\hline $\begin{array}{l}\text { Ferrous fumarate } \\
\text { with folic acid }\end{array}$ & Tablet & $322 \mathrm{mg}$ & $106 \mathrm{mg}$ & 1.25 \\
\hline Ferric maltol & Tablet & $30 \mathrm{mg}$ & $30 \mathrm{mg}$ & 47.60 \\
\hline Sodium feredate & Liquid & $190 \mathrm{mg} / 5 \mathrm{~mL}$ & $27.5 \mathrm{mg} / 5 \mathrm{~mL}$ & 8.37 \\
\hline $\begin{array}{l}\text { Multivitamins } \\
\text { with iron }\end{array}$ & Various & Various & Up to $14 \mathrm{mg}$ & $\sim 1.00 \S$ \\
\hline
\end{tabular}

*Indicative approximate cost per 28 days calculated from drug tariff prices for preparations available on prescription (British National Formulary (BNF)-February 2021). Figures based on once-daily dosing for all standard preparations (50-100 mg elemental iron daily), and licenced dose of $30 \mathrm{mg}$ two times a day for ferric maltol. Exact prices will vary with local purchasing arrangements.

tFerrous sulfate $200 \mathrm{mg}$ tablets are available for purchase at pharmacies in the UK (approximate cost- $\mathrm{f} 2.50$ for 28 days for $200 \mathrm{mg}$ once a day).

¥Modified release (MR) preparations are indicated in the BNF as less suitable for prescribing.

$\S$ Available for over-the-counter purchase at supermarkets and pharmacies.

a randomised trial comparing treatment regimes in subjects with IDA, $60 \mathrm{mg}$ elemental iron two times a day produced a faster rate of $\mathrm{Hb}$ rise than $120 \mathrm{mg}$ on alternate days (ie, half the equivalent daily dose), though similar $\mathrm{Hb}$ increments were seen with alternate day dosing after the same total dose had been given, with a significantly lower prevalence of nausea. ${ }^{120}$

Intermittent oral iron (defined as less frequently than daily) has been reported to be at least as effective as daily dosing in raising $\mathrm{Hb}$ levels in young women and during pregnancy, although less effective in boosting iron stores in the short-term. ${ }^{135}{ }^{136}$ Intermittent oral iron is associated with a lower incidence of GI adverse events in pregnant women (relative risk 0.56 ; 95\% CI 0.37 to $0.84) .^{137}$

The optimal drug, dosage and timing of oral IRT for adults with IDA are not clearly defined, and the effect of alternate day therapy on compliance and ultimate haematological response are unclear. Based on the available literature, a once daily dose of 50-100 mg of elemental iron (eg, one ferrous sulfate $200 \mathrm{mg}$ tablet a day) taken in the fasting state may be the best compromise option for initial treatment. Whatever agent and regimen are chosen, it is essential to monitor the initial haematological response, and modify as appropriate with apparent therapeutic failure.

The best option for patients with significant intolerance to oral IRT (usually GI disturbance) is also unclear. Depending on the individual, oral ferric maltol, alternate day oral iron and parenteral iron are all options. The standard practice of switching to a different traditional iron salt is not supported by evidence.

Ferric maltol is a relatively new preparation, which is licenced for the treatment of IDA of any cause. ${ }^{138} 139$ In patients with inactive IBD, previous intolerance to or failure of traditional iron salts and moderate IDA $(\mathrm{Hb}>95 \mathrm{~g} / \mathrm{L}), 12$ weeks of treatment with ferric maltol normalised the $\mathrm{Hb}$ in $63 \%-66 \%$ of cases. ${ }^{138140} \mathrm{GI}$ side effects and overall rates of treatment cessation were comparable to placebo. ${ }^{138}$ Due to a relatively low iron content, the rate of iron loading is comparatively slow with ferric maltol, but iron loading and tolerance were maintained during a year of active treatment, with normalisation of $\mathrm{Hb}$ in $89 \%$ of cases. ${ }^{139}$ Although more expensive than traditional iron salts, ferric maltol is considerably less expensive than parenteral irons.

Blood transfusion is rarely required to treat IDA, first because most patients with slowly developing anaemia adapt to the resulting physiological stress. Second, as parenteral iron reliably produces a clinically meaningful $\mathrm{Hb}$ response with a week, it should always be considered as an alternative. Transfusion should therefore be reserved for those with severe symptomatic and/ or circulatory compromise. If used, packed red cells should be transfused in accordance with established good practice guidelines, ${ }^{141}$ and a target $\mathrm{Hb}$ of $70-90 \mathrm{~g} / \mathrm{L}(80-100 \mathrm{~g} / \mathrm{L}$ in those with unstable coronary artery disease) would be reasonable. Since a unit of packed red cells contains about $200 \mathrm{mg}$ of elemental iron, it will not replenish the iron store deficit in severe IDA, and so restrictive transfusion should be followed by adequate iron replacement.

There should be a prompt and measurable haematological response to the initiation of IRT, and early monitoring should detect those patients not responding to or intolerant to oral iron. Failure to respond to oral iron has many causes including non-compliance, malabsorption, systemic disease, bone marrow pathology, haemolysis, continued bleeding and concurrent deficiency of vitamin B12 or folic acid.

The absence of an $\mathrm{Hb}$ rise of at least $10 \mathrm{~g} / \mathrm{L}$ after 2 weeks of daily oral IRT is strongly predictive of subsequent failure to achieve a sustained haematological response (sensitivity 90.1\%, specificity $79.3 \%$ for adequate subsequent response). ${ }^{142}$ In this situation, parenteral iron is more effective than continuing traditional oral therapy. ${ }^{142}$

Logistically it may be difficult to arrange monitoring 2 weeks after starting oral IRT in all cases. Indeed because of the lower doses of iron used in alternate day regimens, a 28-day review may be more appropriate. ${ }^{132}$ At this point, a rise in $\mathrm{Hb}$ of 20 $\mathrm{g} / \mathrm{L}$ or into the normal range would be accepted as an adequate response. $^{36}$ Whichever monitoring regimen is used, intolerance and/or ineffectiveness should be managed promptly and appropriately.

For patients with intolerance or failure of $\mathrm{Hb}$ response at the 2-4 weeks point, alternate day traditional iron salts (if not already used) or ferric maltol may be alternatives to parenteral iron on those with mild-moderate anaemia $(\mathrm{Hb}>95 \mathrm{~g} / \mathrm{L})$. The tolerability and response should be assessed, and failure of the $\mathrm{Hb}$ to rise by $10 \mathrm{~g} / \mathrm{L}$ at 4 weeks for alternate day iron, or 6 weeks for ferric maltol, indicates the need for parenteral IRT. ${ }^{132} 140$

Regular $\mathrm{Hb}$ monitoring is recommended to ensure an ultimately satisfactory response. The optimal interval is not clear, but every 4 weeks until the $\mathrm{Hb}$ is in the normal range seems reasonable. After normalisation of the $\mathrm{Hb}$, oral iron needs to be continued to replenish the iron stores. Traditionally it has been recommended that oral iron is continued for 2-3 months to do this. However, the duration required and indeed the appropriate measure of true iron repletion are both unclear. In healthy, almost iron-replete subjects, 2 months of continued iron was considered sufficient. ${ }^{143}$ However, in patients with chronic disease, continuing blood loss, impaired absorption or GI inflammatory 
Table 4 A comparison of intravenous iron preparations available in the UK (February 2021)

\begin{tabular}{|c|c|c|c|c|}
\hline Formulation & Iron dose & Test dose & Min infusion & $\operatorname{Cos} t / f^{*}$ \\
\hline Iron sucrose & $200 \mathrm{mg}$ per injection & Yes & $30 \mathrm{~min}$ & 102 \\
\hline $\begin{array}{l}\text { Ferric } \\
\text { carboxymaltose }\end{array}$ & $\begin{array}{l}\text { TDR—max single dose } 20 \mathrm{mg} / \\
\mathrm{kg} \text { or } 1000 \mathrm{mg} \ddagger\end{array}$ & No & $15 \min$ & $154.23+$ \\
\hline $\begin{array}{l}\text { Ferric } \\
\text { derisomaltose }\end{array}$ & $\begin{array}{l}\text { TDR—max single dose } \\
20 \mathrm{mg} / \mathrm{kg}\end{array}$ & No & $15-30 \mathrm{mint}$ & 169.50 \\
\hline Iron dextran & $200 \mathrm{mg}$ per injection & Yes & $40 \mathrm{~min}$ & 79.7 \\
\hline Iron dextran & $\begin{array}{l}\text { TDR—max single dose } \\
20 \mathrm{mg} / \mathrm{kg}\end{array}$ & Yes & 4-6 hours & 79.7 \\
\hline
\end{tabular}

*Indicative approximate cost per $1000 \mathrm{mg}$ elemental iron calculated from National Health Service prices (British National Formulary—February 2021). Administration costs not included.

tDependent on dose.

$\neq$ Whichever is the lower.

TDR, total dose replacement.

disease (where iron is lost from the GI mucosa), it is likely that a longer period would be required.

\section{Parenteral IRT}

Parenteral IRT replenishes body iron stores more quickly than oral IRT. However, for the majority of patients with IDA, this is not translated into a clinical benefit in terms of rise in $\mathrm{Hb} .{ }^{144-147}$ The Hb response to parenteral and oral iron is typically similar, ${ }^{148}$ or marginally faster with parenteral iron-for example, $0.7 \mathrm{~g} / \mathrm{L}$ higher after 23 days treatment in postoperative cases. ${ }^{149}$ A course of oral $200 \mathrm{mg}$ ferrous sulfate once a day was as effective as a single ferric carboxymaltose infusion in restoring $\mathrm{Hb}$ after a GI haemorrhage. ${ }^{147}$ Therefore, the oral route is generally preferred on the grounds of cost and convenience with comparable efficacy.

The intravenous route for IRT may however be preferable from the outset in those with ongoing significant bleeding, malabsorption due to GI disease, the combination of iron deficiency and anaemia of inflammation, or issues with administration (eg, severe dysphagia) or compliance. ${ }^{149} 150$ Parenteral iron may also be indicated in those failing to respond to oral IRT due to intolerance, pharmacodynamic failure or continued bleeding. Intravenous IRT has been shown to be superior to continuing oral therapy in cases with IDA that failed to show a significant $\mathrm{Hb}$ rise with oral IRT (defined as an increase of $10 \mathrm{~g} / \mathrm{L}$ or more after 2 weeks), ${ }^{36}$ or had ongoing menorrhagia. ${ }^{117}$

A variety of parenteral iron preparations are available in the UK (table 4), and these all have the advantage of providing a much greater iron load per dose than oral iron. They all are more expensive than traditional oral iron preparations, and there are additional associated costs relating to the facilities, staffing and equipment required for administering infusions. Some preparations (ferric carboxymaltose), iron derisomaltose (previously iron isomaltoside 1000) and (low molecular weight) iron-dextran can effectively replenish total body iron stores in one or two infusions. Iron sucrose requires multiple infusions because the maximum dose per administration is $200 \mathrm{mg}$. Irondextran is rarely used, as the much longer time required for infusion (4-6 hours) means this is much less convenient than the other total dose preparations, which can be given over 15-40 $\min$.

The dose of parenteral iron may be calculated using the original Ganzoni formula. ${ }^{151}$ Modifications using a lower target Hb level (130 g/L) have also been used. ${ }^{145}$ Overall the different intravenous iron formulations appear equivalent in terms of the ultimate haematological response and safety, ${ }^{152}$ but the total dose preparations provide more rapid replenishment of body iron stores, ${ }^{116} 146153154$ usually in just one or two infusions. Monitoring for a satisfactory $\mathrm{Hb}$ response after 2-4 weeks should be undertaken, and then as outlined below.

\section{Treatment of NAID}

The efficacy of IRT for NAID (also termed isolated hypoferritinaemia) is unclear. There are limited studies in adults, with a variety of inclusion criteria and outcomes. A meta-analysis of these concluded that NAID was not significantly associated with physiological impairment assessed objectively by VO2 max or respiratory exchange ratio max (RERmax), and that IRT did not significantly improve either these parameters or maximal heart rate. ${ }^{155}$ There is however evidence that IRT may provide subjective improvement of fatigue, mental quality of life and subjective cognitive function in premenopausal women. ${ }^{156-160}$ Therefore, given the safety of the available iron preparations, it would be reasonable to offer treatment for NAID if symptomatic.

\section{Monitoring after IRT}

The optimal follow-up protocol after IRT remains to be established, but given the possibility of recurrent IDA indicating underlying disease, and the prevalence of persistent anaemia after IRT seen in some real-world studies, ${ }^{161}$ periodic monitoring is advised. Once the $\mathrm{Hb}$ has reached the normal range, a check blood count 3-monthly for 12 months and then 6-monthly for 2-3 years would be reasonable. Although SF is a reliable measure of total body iron stores, there are insufficient data to recommend routine ferritin monitoring.

\section{Safety of IRT}

GI adverse effects (such as nausea, diarrhoea, constipation) are much commoner with oral preparations, and there is no convincing evidence for the superiority of any of the readily available traditional iron salts. ${ }^{162} 163$ GI side effects are significantly commoner with oral ferrous sulfate than placebo (OR 2.32 (95\% CI 1.74 to 3.08$)$ ) or parenteral iron (OR 3.05 (95\% CI 2.07 to 4.48$)$ ), and there is no dose-effect relationship over the range 50-400 mg of elemental iron per day. ${ }^{123}$ Despite the high prevalence of mild side-effects, the rates of discontinuation in clinical trials due to adverse events are relatively low (0\%-24\%), though higher than rates of discontinuation of parenteral iron (0\%-18\%). ${ }^{126144145149164165}$ Discontinuation of oral IRT seems to be commoner in observational and population studies, with reported rates of up to $40 \% .^{166167}$

Infusion-related reactions are uncommon with modern intravenous iron preparations, but hypersensitivity-type and infusion reactions (approximate incidence-0.5\%) are commoner than with oral iron or placebo. ${ }^{152}$ Serious adverse reaction rates are low, however, and similar for oral and parenteral iron preparations. $^{168}$

Caution is advised regarding the use of parenteral iron in the context of acute and chronic infection, although studies have consistently shown no significant increase in clinically important infective episodes associated with the use of parenteral IRT. $^{152} 168169$ Infection should not be regarded as a contraindication to parenteral IRT if the risk/benefit assessment favours treatment of the anaemia, though it should be withheld in those with ongoing bacteraemia.

Hypophosphataemia has been reported with all parenteral iron preparations. This seems to relate to the molecules complexed to the iron, rather than the iron itself. Rates of hypophosphataemia are higher with ferric carboxymaltose $(58 \%)$ than with iron derisomaltose $(4 \%)$ or iron sucrose $(1 \%)$, but 
the clinical importance of this has not been established. Most of the episodes are biochemically moderate (serum phosphate in the range $0.32-0.64 \mathrm{mmol} / \mathrm{L}$ ) and asymptomatic, and resolve without the need for intervention. ${ }^{170}{ }^{171}$ However, because of the rare association with hypophosphataemic osteomalacia, the Medicines and Healthcare products Regulatory Agency issued a recommendation in 2020 advising that serum phosphate levels should be monitored in those with risk factors for hypophosphataemia, and in those receiving long-term or multiple high-dose infusions of ferric carboxymaltose. ${ }^{172}$

\section{SPECIAL SITUATIONS Young women}

24. IDA is common in young women, and major contributory factors include menstrual losses, pregnancy and poor dietary intake (evidence quality-high, consensus-100\%, statement strength-strong).

25 . Underlying GI pathology is uncommon in young women with IDA, and so after screening for CD, we recommend that further investigation is warranted only if there are additional clinical features of concern-as detailed in the text (evidence quality-moderate, consensus-92\%, statement strength-strong).

26. If GI investigation in a pregnant woman is deemed necessary prior to delivery, gastroscopy and (after the first trimester) MR enterography are considered safe in pregnancy (evidence quality-low, consensus-91\%, statement strength—strong).

The prevalence of IDA in otherwise healthy premenopausal women is $5 \%-12 \% .{ }^{173} 174$ It usually reflects some combination of dietary insufficiency, menstrual losses, and increased demand for iron in pregnancy and breastfeeding. ${ }^{175}$

Multiple studies have analysed the yield of GI investigation in young women with IDA. ${ }^{176-183}$ As CD is found in up to $4 \%$ of cases, all premenopausal women with IDA should be considered for serological screening. Malignant tumours can occur in otherwise asymptomatic premenopausal women, but they are extremely uncommon-two studies suggesting a higher prevalence ${ }^{182183}$ have been criticised on the grounds of selection bias.

In general, therefore IDA in young women is not an indication for endoscopic investigation. There are however various situations where direct endoscopic investigation of premenopausal women with IDA may be appropriate. These include ${ }^{1125}$ :

- Age over 50-as age is a strong predictor of the risk of malignancy in IDA.

- Non-menstruating women-for example, following hysterectomy.

- Associated red flag symptoms, as outlined in NICE referral guidelines. $^{2324184}$

- Indications of a major genetic risk of GI pathology-for example, colorectal cancer affecting two first-degree relatives, or one first-degree relative affected before the age of 50 years.

- Recurrent or persistent IDA which appears disproportionate to other potential causes of iron deficiency such as menstrual losses-accepting that this is usually a rather subjective judgement.

Mild IDA is common in pregnancy. ${ }^{22} 175$ IRT should be encouraged, but there is no need for endoscopic investigation unless there are pointers to the presence of underlying GI pathology in the history or on coeliac serology. If further investigation prior to delivery is felt to be warranted, gastroscopy, duodenal biopsy and MR enterography are considered safe for mother and fetus in pregnancy, though the National Radiological Protection Board considers it prudent to avoid MRIs in the first trimester. There are insufficient data on the safety of colonoscopy in pregnancy, and because of the potential to cause serious adverse events, it should be only be considered for the most pressing of indications. ${ }^{185}$

\section{Young men}

27. Confirmed IDA is uncommon in young men, but when found we recommend that it warrants the same investigational algorithm as for older people (evidence quality-moderate, consensus-100\%, statement strength-strong).

IDA is relatively uncommon in young men, but the yield of pathology on examination of the GI tract is considerably higher than in women of the same age. ${ }^{25} 186$ IDA in young men therefore generally warrants the same investigational algorithm as described for older people, unless a convincing explanation for it is evident.

\section{The elderly}

28. Iron deficiency is common in the elderly, and is often multifactorial in aetiology (evidence quality-high, consensus-100\%, statement strength-strong).

29. We recommend that the risks and benefits of invasive endoscopic and alternative investigation(s) are carefully considered in those with major comorbidities and/or limited performance status (evidence quality-medium, consensus-92\%, statement strength—strong).

Anaemia is common in older people, affecting more than $20 \%$ of those over the age of 85 years, and more than $50 \%$ of residential/nursing home residents. The aetiologies responsible for anaemia in this age group are complex, and often multiple. Iron deficiency is however a contributory factor in about half of cases, sometimes associated with deficiencies of vitamin B12 and/or folate. Anaemia in older patients has been shown to contribute to worsening of physical performance, cognitive function and frailty. ${ }^{187-190}$

Iron deficiency in the elderly has many potential contributory causes including poor diet, reduced iron absorption, occult blood loss, medication (eg, aspirin) and chronic disease (eg, CKD, $\mathrm{CHF}$ ). Blood loss from mucosal lesions may be compounded by concurrent antiplatelet/anticoagulant therapy. Older patients are more likely than younger ones to have more than one contributing cause. The diagnosis can be confirmed by measurement of ferritin and transferrin saturation, though the former may be difficult to interpret in the presence of coexisting inflammatory conditions.

Evaluation of the upper and lower GI tract should be considered if IDA has been confirmed, though CT colonography may be a more attractive alternative to colonoscopy for some older individuals. The prevalence of malignancy and of dual unrelated pathology in this age group strengthens the case for imaging both the upper and lower GI tract. ${ }^{17}$ However, the potential risks and benefits of invasive investigation should be carefully weighed up in older adults, particularly those who are frail, have significant comorbidities or reduced life expectancy. Furthermore, these considerations should be discussed with each patient and his/her family, taking their views into account.

As in other age groups, the cause of IDA cannot always be established despite thorough investigation. Oral iron administration remains the standard first-line treatment in most patients, but parenteral iron is a convenient and relatively safe alternative if oral iron is not tolerated.

\section{Specific comorbidities}

30. Functional iron deficiency (FID) is a common contributory factor to the anaemia associated with advanced chronic kidney 
disease (CKD) (evidence quality—bigh, consensus-92\%, statement strength-strong).

31. Iron deficiency is common in chronic heart failure (CHF), and is often multifactorial (evidence quality-high, consensus— $92 \%$, statement strength—strong).

32. Parenteral IRT may improve symptoms and quality of life in CHF with FID (evidence quality - moderate, consensus-100\%, statement strength—strong).

33. In the management of iron deficiency associated with CKD or CHF, reference to the appropriate specialist published guidelines is recommended (evidence quality-moderate, consensus - $92 \%$, statement strength—strong).

34. IDA is a common manifestation of IBD, particularly when the disease is active (evidence quality — high, consensus-100\%, statement strength-strong).

35. Intolerance and malabsorption of oral IRT can be particular problems in the treatment of IBD-associated IDA, and parenteral IRT may be required (evidence quality-medium, consensus-100\%, statement strength—strong).

Several chronic disorders such as CKD, CHF and IBD are associated with iron deficiency. While the cause of iron deficiency in these conditions is often multifactorial, altered production of hepcidin and ferroportin is thought to be a major contributory factor. Nevertheless, the presence of iron deficiency should be actively sought because IRT may improve patient outcomes. ${ }^{191}$ The assessment and management of iron deficiency in these conditions do have certain nuances, and consultation with detailed published guidelines is therefore recommended. Similar clinical considerations apply to other inflammatory disorders such as rheumatoid arthritis.

\section{Chronic kidney disease}

Anaemia is a frequent complication of CKD. CKD is a potential cause for anaemia in anyone with a glomerular filtration rate (GFR) of less than $60 \mathrm{~mL} / \mathrm{min} / 1.73 \mathrm{~m}^{2}$. As the prevalence of anaemia increases with deteriorating renal function, CKD is especially likely to be the cause of anaemia when the GFR is less than $30 \mathrm{~mL} / \mathrm{min} / 1.73 \mathrm{~m}^{2}$. The investigation and management of anaemia in CKD is a complex area, and readers are advised to consult specific guidelines relevant to UK practice published by NICE and the Renal association for more detailed recommendations. ${ }^{41} 192193$

The causes are anaemia in CKD are multifactorial. Iron deficiency is a major element, but multiple other mechanisms (eg, haemolysis, plasma cell dyscrasias) may also contribute towards the development of anaemia, hence the requirement for detailed haematological investigation. The causes of iron deficiency in CKD are also multifactorial. Renal failure itself contributes, but this may also be compounded by reduced iron intake, reduced iron absorption and blood loss via either the GI tract or other routes such as dialysis and phlebotomy. ${ }^{194}$

Assessment of iron deficiency in CKD can be difficult. Measurement of ferritin and transferrin saturation may be helpful, but the interpretation of results is not the same as in patients who do not have CKD. Specifically, absolute iron deficiency in CKD has been defined as transferrin saturation $\leq 20 \%$, with SF $\leq 100$ $\mu \mathrm{g} / \mathrm{L}$ (in predialysis and peritoneal dialysis patients) or $\leq 200$ $\mu \mathrm{g} / \mathrm{L}$ (in haemodialysis patients). ${ }^{194}$

Patients with CKD may of course also have GI pathology underlying their confirmed iron deficiency. The decision about the need for endoscopic evaluation of the upper and lower GI tract in CKD can be difficult, and should ideally be made in conjunction with a nephrologist. However, the majority of CKD patients with confirmed IDA warrant GI investigation as long as they are fit enough to undergo these procedures.

The management of iron deficiency in the context of CKD is beyond the scope of these guidelines and is discussed in detail elsewhere. ${ }^{41} 192193$ Treatment is usually initiated and monitored by the nephrology team. In brief, oral iron replacement may be tried in patients who are predialysis. However, intravenous IRT is required if this is not tolerated or ineffective, or if dialysis has been commenced. Other treatments for anaemia such as erythropoietin may also be needed, but these should be managed by the nephrology team.

\section{Chronic heart failure}

Evidence of some degree of iron deficiency, as defined by an $\mathrm{SF}<100 \mu \mathrm{g} / \mathrm{L}$ and/or a transferrin saturation of $<20 \%$, is found in $40 \%-70 \%$ of cases with CHF. ${ }^{195-198}$ The causes are again multifactorial with malabsorption, malnutrition and GI blood loss (potentially exacerbated by anticoagulants or antiplatelet agents) all potentially contributing. In addition, the chronic inflammatory state present in many patients with CHF can lead to increased hepcidin release by the liver, resulting in reduced iron absorption/mobilisation.

Patients with CHF should be screened for iron deficiency by measurement of ferritin and transferrin saturation. ${ }^{195-198}$ Endoscopic evaluation of the upper and lower GI tract should be considered if they have evidence of absolute iron deficiency (see the Definitions section) to exclude treatable GI causes. Decisions about the need for and safety of endoscopic evaluation should ideally be made in conjunction with the cardiology team.

The majority however have FID rather than absolute iron deficiency. Nevertheless, both forms of ID are associated with reduced functional capacity, impaired quality of life and poorer prognosis in CHF. ${ }^{191-194}$ Patients who meet the above criteria for iron deficiency in this condition should therefore be considered for intravenous IRT, ${ }^{195}$ as this has been shown to have prognostic benefit in meta-analyses. ${ }^{196} 197$ No prognostic benefit has been demonstrated for oral iron, and this is best avoided as in CHF it may be poorly absorbed due to gut oedema, and is frequently associated with side-effects. ${ }^{195}$ Specific guidelines should be consulted for detailed recommendations about the investigation and management of iron deficiency in this patient group. ${ }^{198}$

\section{Inflammatory bowel disease}

A third of patients with active IBD are estimated to have iron deficiency, though other mechanisms including vitamin B12 and folate deficiency, marrow suppression due to the anaemia of chronic disease, and overt blood loss may all contribute to the anaemic state. ${ }^{199} \mathrm{SF}$ levels of up to $100 \mu \mathrm{g} / \mathrm{L}$ in the presence of inflammation may still reflect iron deficiency, ${ }^{200}$ and so an estimate of transferrin saturation may be helpful. The absorption of oral iron may be impaired by the systemic inflammatory process, ${ }^{148} 201$ as well as by small bowel involvement and/or previous surgery, and this may favour intravenous IRT in some cases. ${ }^{164}$

Current European guidelines suggest that oral IRT in patients with IBD should contain no more than $100 \mathrm{mg}$ elemental iron a day. ${ }^{200}$ Intravenous iron is indicated for those who are intolerant of oral iron and have moderate to severe IDA $(\mathrm{Hb}<100$ $\mathrm{g} / \mathrm{L}) .{ }^{148} 164200$ Optimising nutritional and pharmacological management to bring active IBD into remission would be expected to help improve IDA metrics and response to iron therapy. ${ }^{200} 201$ 
It has been suggested that patients with IBD and IDA should be monitored for recurrent iron deficiency every 3 months for at least a year after correction, and periodically thereafter. ${ }^{200}$ Recurrent IDA may indicate persistent intestinal inflammatory activity even in the face of clinical remission and normal inflammatory biomarkers. ${ }^{200}$

\section{GI surgery}

36. IDA is common following resection or bypass surgery involving the stomach and/or small bowel, including bariatric surgery (evidence quality-high, consensus-92\%, statement strength—strong).

37. In new presentations of IDA, we recommend that a history of GI or bariatric surgery should not preclude a search for other causes of IDA (evidence quality-low, consensus-85\%, statement strength—strong).

Resection or bypass surgery involving the stomach and/ or small bowel generally predisposes to IDA. ${ }^{202}$ This includes the expanding population with a history of bariatric surgery, including sleeve gastrectomy. Reduced nutritional intake and malabsorption are probably the major underlying mechanisms, ${ }^{203}$ and therefore IDA in this situation may occur in the context of other nutritional deficiencies_-in particular of vitamin B12.

The prevalence of IDA depends on the specific diagnostic criteria employed, but it is found in approximately a quarter of subjects 2 years following Roux-en-Y gastric bypass, and is markedly commoner in women, ${ }^{204-206}$ and in those with preoperative evidence of low iron stores. ${ }^{202}$ The figure for sleeve gastrectomy is probably lower. ${ }^{202} 207$

Predictably, the yield of other causative lesions on BDE is lower in individuals with IDA and a history of GI surgery than in those without. ${ }^{208}$ Nevertheless, it is unsafe to automatically attribute IDA to previous surgery without excluding other possibilities, particularly in those at risk of underlying GI malignancy-bearing in mind that partial gastrectomy may predispose to the later development of cancer in the gastric remnant. ${ }^{209}$

Without supplementation, the percentage prevalence of IDA tends to increase over the first 10 postoperative years. ${ }^{203-206}$ Long-term oral IRT is often effective, though because of underlying malabsorption this is not always the case, and intravenous therapy may be required. ${ }^{210} 211$

\section{SERVICE CONSIDERATIONS}

38. We recommend that all service providers should have clear points of referral and management pathways for patients with IDA (evidence quality-low, consensus-100\%, statement strength-strong).

39. To ensure efficient use of resources, we recommend that IDA pathways should be delivered by a designated team led by a senior clinician (evidence quality-low, consensus-100\%, statement strength-strong).

40. We recommend that service providers should aim to have an ambulatory care base for the administration of parenteral iron (evidence quality-low, consensus-100\%, statement strength—strong).

\section{Organisation}

IDA has a considerable impact on referrals for urgent investigation for suspected cancer and non-elective services. This is due to the prevalence of IDA in the population, difficulty in distinguishing IDA from other causes of anaemia, and in some areas the absence of a dedicated referral pathway for the management of anaemia. In many hospitals IDA is no longer the prime interest of haematology, so becoming an 'orphan' condition without clinical leadership. This can lead to duplication of services, prolonged referral pathways and inappropriate investigation. ${ }^{212}$

Anaemia is common in elderly patients and those with multiple comorbidities. The anaemia of chronic disease can mimic IDA, and in a study of fast-track referrals with suspected IDA, the diagnosis was confirmed in only $11 \%$ of cases. ${ }^{213}$ Therefore it is important to establish at an early stage that anaemia is due to iron deficiency. Fortunately, artificial intelligence or smart testing algorithms embedded within red cell laboratory analysers (reflex testing) are now available and can include specific recommendations for further management to primary care ${ }^{214}$ including referral to a dedicated electronic IDA clinical assessment service which supports appropriate clinical interaction between primary and secondary care before any further investigation. ${ }^{215}$ Given the increasing fragmentation of care across providers, this should include a facility for interrogating electronic healthcare records for any previously documented diagnosis of IDA, and the results of prior investigations including oesophago-gastroduodenoscopy, colonoscopy and CT colonography.

For a dedicated IDA service to deliver highly effective care, the four essential components are ${ }^{1}$ confirmation of IDA, ${ }^{2}$ timely access to appropriate investigation (if not already investigated) ${ }^{3}$ ensuring appropriate IRT (with long-term therapy when needed) and ${ }^{4}$ strong clinical leadership. ${ }^{49-51216}$

IDA services can also provide an alternative pathway for patients found to have more severe anaemia, and who otherwise might have been referred for emergency hospital admission. Estimates based on data from Hospital Episode Statistics 2017 suggest that up to 97781 patients are admitted in England each year with IDA as the primary diagnosis, which is $72 \%$ higher than in 2012. Similar increases over the same period are seen for non-elective hospital spells (days in hospital) with IDA as a secondary diagnosis.

\section{Costs associated with IDA}

The estimated costs incurred by the NHS in the management of IDA in secondary care in England rose from $£ 65.8$ million in $2012 / 2013$ to $£ 90.6$ million in $2017 / 2018 .^{217}$ The vast majority of these costs arose from patient managementoutpatient or emergency inpatient referral, and subsequent investigation-rather than from treatment of the iron deficiency. Clearly, treatment costs following the diagnosis of CD for example are very different to those associated following occult GI blood loss in patients taking anticoagulants. Few studies have analysed the investigation and management costs of IDA, but it is recognised from data collected as part of the national blood transfusion audits that costs arising from unnecessary emergency hospital admission could be substantially reduced if alternative patient referral pathways were readily available to support ambulatory care. ${ }^{217}$

While most oral iron supplements are cheap, they are not always well-tolerated, often due to GI side-effects. Newer oral iron supplements are better tolerated, but more expensive (table 3). Intravenous IRT is often necessary for patients with comorbidities which impair iron absorption. While there are several studies reporting the cost-effectiveness of intravenous iron preparations in comparison to oral IRT for specific conditions such as CKD, CHF and IBD, it is the associated comorbidity which accounts for the 
improved cost-effectiveness of intravenous iron in these circumstances. $^{218}$

\section{PATIENT SUMMARY}

Iron is a nutrient essential to life. It is used in the body to produce many cellular proteins, and an important one is $\mathrm{Hb}$, the oxygen-binding protein found in red blood cells. A shortage of iron in the body prevents the production of these proteins, and so one of the major consequences is that the rate and quality of red cell production in the bone marrow is reduced-a condition called IDA.

IDA is common worldwide, and can result in many symptoms including extreme fatigue and breathlessness. It can generally be diagnosed by simple blood tests, and remedied by treatment with IRT given by mouth or injection.

There are many causes of iron deficiency, including a poor dietary intake, and failure to absorb dietary iron in the upper bowel. Because blood is iron-rich, it can also result from the gradual loss of blood from the body over the course of a long period-and this is a common cause of IDA.

Studies have shown that about a third of adults over the age of 50 with IDA in the UK have an underlying bleeding abnormality, most commonly in the stomach or lower bowel. In about a third of these, the abnormality proves to be a cancer. It is therefore recommended that unexplained IDA in this age group is investigated by examining these areas, even if there are no other relevant symptoms. This is usually done by endoscopy, though CT scanning is an alternative for assessing the lower bowel.

\section{Research recommendations}

Diagnosis

- New digital approaches to identifying IDA.

Investigation

- FIT and risk stratification in IDA.

- Role of screening for atrophic gastritis by histology or serology (eg, Gastropanel).

- The role of newer diagnostic modalities for example, colon capsule.

Treatment

- Optimal dosage regimes for oral IRT.

- Optimal target of treatment with oral IRT.

- Role of newer iron salts (eg, ferric maltol) when traditional salts have failed.

- Optimal place of intravenous iron in acute and chronic settings.

- The role of laboratory investigations in predicting nonresponse to oral IRT.

Special situations

- Appropriate investigative strategies in menstruating women.

- Epidemiology, investigation and treatment of NAID.

Correction notice This article has been corrected since it published Online First. Affiliation number 6 and table 4 have been updated.

Twitter Neeraj Bhala @nijbhala, D Mark Pritchard @gastrolivuni, Reena Sidhu@ drreenasidhu1, Ajay M Verma @UKGastroDr and Andrew F Goddard @bodgoddard

Contributors All coauthors contributed material for and amendments to the original draft, and approved the final version for submission.

Funding The authors have not declared a specific grant for this research from any funding agency in the public, commercial or not-for-profit sectors.

Competing interests ILPB: Vifor advisory board, Pharmcosmos advisory board: PI for Feraccru studies. RL: Vifor Advisory Board, NHS England advisor. MP: Trio Medicines (research funding); IPSEN, Advanced Accelerator Applications, Mayoly
Spindler laboratories (consultancies). AMV, WT, RS, CK, DC, NB, SS, AFG, JS: none declared.

Patient and public involvement Patients and/or the public were involved in the design, or conduct, or reporting, or dissemination plans of this research. Refer to the Methods section for further details.

Patient consent for publication Not required.

Provenance and peer review Not commissioned; externally peer reviewed.

Open access This is an open access article distributed in accordance with the Creative Commons Attribution Non Commercial (CC BY-NC 4.0) license, which permits others to distribute, remix, adapt, build upon this work non-commercially, and license their derivative works on different terms, provided the original work is properly cited, appropriate credit is given, any changes made indicated, and the use is non-commercial. See: http://creativecommons.org/licenses/by-nc/4.0/.

\section{ORCID iDs}

Jonathon Snook http://orcid.org/0000-0002-3172-2722

Neeraj Bhala http://orcid.org/0000-0003-2502-1177

Ian L P Beales http://orcid.org/0000-0003-1923-3237

Robert PH Logan http://orcid.org/0000-0003-1133-0868

D Mark Pritchard http://orcid.org/0000-0001-7971-3561

Wayne Thomas http://orcid.org/0000-0003-3349-947X

Ajay M Verma http://orcid.org/0000-0002-6432-3357

Andrew F Goddard http://orcid.org/0000-0002-0130-7966

\section{REFERENCES}

1 Kassebaum NJ, GBD 2013 Anemia Collaborators. The global burden of anemia. Hematol Oncol Clin North Am 2016:30:247-308.

2 World Health Organisation. Worldwide prevalence of anaemia 1993-2005, who vitamin and mineral nutrition information system. Geneva:WHO, 2008. https:// apps.who.int/iris/handle/10665/43894? search-result=true\&query=worldwide+ prevalence + of +anaemia\&scope $=\% 2 F \& r p p=10 \&$ sort by $=$ score \&order $=$ desc

3 Guralnik JM, Eisenstaedt RS, Ferrucci L, et al. Prevalence of anemia in persons 65 years and older in the United States: evidence for a high rate of unexplained anemia. Blood 2004;104:2263-8.

4 Lopez A, Cacoub P, Macdougall IC, et al. Iron deficiency anaemia. Lancet 2016;387:907-16.

5 Pasricha S-R, Tye-Din J, Muckenthaler MU, et al. Iron deficiency. Lancet 2021;397:233-48.

6 Goddard A, Phillips C. Ferronomics. An economic report on the hidden cost of anaemia management. Vifor Pharma, 2014.

7 Rockey DC, Cello JP. Evaluation of the gastrointestinal tract in patients with irondeficiency anemia. N Eng/ J Med 1993:329:1691-5.

8 Cook IJ, Pavli P, Riley JW, et al. Gastrointestinal investigation of iron deficiency anaemia. Br Med J 1986:292:1380-2

9 Zuckerman G, Benitez J. A prospective study of bidirectional endoscopy (colonoscopy and upper endoscopy) in the evaluation of patients with occult gastrointestinal bleeding. Am J Gastroenterol 1992;87:62-6.

10 Hardwick RH, Armstrong CP. Synchronous upper and lower gastrointestinal endoscopy is an effective method of investigating iron-deficiency anaemia. $\mathrm{Br}$ J Surg 1997:84:1725-8

11 James MW, Chen C-M, Goddard WP, et al. Risk factors for gastrointestinal malignancy in patients with iron-deficiency anaemia. Eur J Gastroenterol Hepatol 2005; 17:1197-203

12 Kepczyk T, Kadakia SC. Prospective evaluation of gastrointestinal tract in patients with iron-deficiency anemia. Dig Dis Sci 1995;40:1283-9.

13 Lucas CA, Logan EC, Logan RF. Audit of the investigation and outcome of irondeficiency anaemia in one health district. J R Coll Physicians Lond 1996;30:33-6.

14 Yates JM, Logan ECM, Stewart RM. Iron deficiency anaemia in general practice: clinical outcomes over three years and factors influencing diagnostic investigations. Postgrad Med J 2004;80:405-10.

15 Thumbe A, Quraishi MN, Dabhi K. PTU-060 iron deficiency anaemia in plain sight at the front door in the Midlands. Gut2019;68:A147.

16 McIntyre AS, Long RG. Prospective survey of investigations in outpatients referred with iron deficiency anaemia. Gut 1993;34:1102-7.

17 Stone $\mathrm{H}$, Almilaji $\mathrm{O}$, John $\mathrm{C}$, et al. The dedicated iron deficiency anaemia clinic: a 15-year experience. Frontline Gastroenterol 2020;58. doi:10.1136/ flgastro-2020-101470. [Epub ahead of print: 10 Sep 2020].

18 Goddard AF, James MW, McIntyre AS, et al. Guidelines for the management of iron deficiency anaemia. Gut 2011;60:1309-16.

19 BSG Guidelines Advice Document, 2018. Available: https:/www.bsg.org.uk/ resource-type/guidelines/page/3/ [Accessed 16 Feb 2021].

20 Brouwers MC, Kho ME, Browman GP, et al. Agree II: advancing Guideline development, reporting and evaluation in health care. CMAJ 2010;182:E839-42.

21 Guyatt GH, Oxman AD, Vist GE, et al. Grade: an emerging consensus on rating quality of evidence and strength of recommendations. BMJ 2008;336:924-6. 
22 Stewart T, Lambourne J, Thorp-Jones D, et al. Implementation of early management of iron deficiency in pregnancy during the SARS-CoV-2 pandemic. Eur J Obstet Gynecol Reprod Biol 2021;258:60-2.

23 NICE. NICE guideline NG12 - Suspected cancer : recognition and referral. London: NICE, 2015. https://www.nice.org.uk/guidance/ng12/resources/suspected-cancerrecognition-and-referral-pdf-1837268071621

24 Hamilton W, Lancashire R, Sharp D, et al. The importance of anaemia in diagnosing colorectal cancer: a case-control study using electronic primary care records. $\mathrm{Br}$ J Cancer 2008;98:323-7.

25 Almilaji 0, Smith C, Surgenor S, et al. Refinement and validation of the IDIOM score for predicting the risk of gastrointestinal cancer in iron deficiency anaemia. BMJ Open Gastroenterol 2020;7:e000403.

26 Lewis SM, Bain BJ, Bates I. Dacie and Lewis Practical Haematology. 9th edn. London: Churchill Livingstone, 2001.

27 Jolobe OM. Diagnosis of iron deficiency anaemia. Arch Dis Child 2005;90:653-4

28 Jolobe OM. Prevalence of hypochromia (without microcytosis) vs microcytosis (without hypochromia) in iron deficiency. Clin Lab Haematol 2000;22:79-80.

29 World Health Organisation. Serum ferritin concentrations for the assessment of iron status and iron deficiency in populations, who vitamin and mineral nutrition information system (WHO/NMH/NHD/MNM/11.2). Geneva:WHO, 2011. https:// apps. who.int/iris/handle/10665/85843? search-result=true\&query=serum+ferritin+ concentrations \&scope $=\% 2 F \& r p p=10 \&$ sort_by $=$ score \&order $=$ desc

30 Guyatt GH, Oxman AD, Ali M, et al. Laboratory diagnosis of iron-deficiency anemia: an overview. J Gen Intern Med 1992;7:145-53.

31 Cook JD, Baynes RD, Skikne BS. Iron deficiency and the measurement of iron status. Nutr Res Rev 1992;5:198-202.

32 Rockey DC, Altayar O, Falck-Ytter Y, et al. AGA technical review on gastrointestinal evaluation of iron deficiency anemia. Gastroenterology 2020;159:1097-119.

33 Fletcher A, Forbes A, Svenson N. Guideline for the laboratory diagnosis of iron deficiency in adults (excluding pregnancy) and children. British Journal of Haematology 2021

34 Cook JD. The measurement of serum transferrin receptor. Am J Med Sci 1999;318:269-76

35 Cook JD, Flowers CH, Skikne BS. The quantitative assessment of body iron. Blood 2003:101:3359-64.

36 Okam MM, Koch TA, Tran M-H. Iron supplementation, response in iron-deficiency anemia: analysis of five trials. Am J Med 2017:130:991.e1-991.e8.

37 Thomas DW, Hinchliffe RF, Briggs C, et al. Guideline for the laboratory diagnosis of functional iron deficiency. Br J Haematol 2013;161:639-48.

38 Tiwari AK, Bhardwaj G, Arora D, et al. Applying newer parameter Ret$\mathrm{He}$ (reticulocyte haemoglobin equivalent) to assess latent iron deficiency (lid) in blood donors-study at a tertiary care hospital in India. Vox Sang 2018;113:639-46.

39 Brugnara C, Schiller B, Moran J. Reticulocyte hemoglobin equivalent (RET He) and assessment of iron-deficient states. Clin Lab Haematol 2006;28:303-8.

40 Macdougall IC, Cavill I, Hulme B, et al. Detection of functional iron deficiency during erythropoietin treatment: a new approach. BMJ 1992;304:225-6.

41 NICE. NICE Guideline NG8 - Chronic kidney disease: managing anaemia. London: NICE, 2015. https://www.nice.org.uk/guidance/ng8/resources/chronic-kidneydisease-managing-anaemia-pdf-51046844101

42 Toki Y, Ikuta K, Kawahara Y, et al. Reticulocyte hemoglobin equivalent as a potential marker for diagnosis of iron deficiency. Int J Hematol 2017;106:116-25.

43 Brugnara C, Laufer MR, Friedman AJ, et al. Reticulocyte hemoglobin content (CHR): early indicator of iron deficiency and response to therapy. Blood 1994;83:3100-1.

44 Mast AE, Blinder MA, Lu Q, et al. Clinical utility of the reticulocyte hemoglobin content in the diagnosis of iron deficiency. Blood 2002;99:1489-91.

45 Urrechaga E, Hoffmann JJML, Bernal A, et al. Reticulocyte hemoglobin content $(\mathrm{MCHr})$ in the assessment of iron deficient erythropoiesis in inflammatory bowel disease. Dig Liver Dis 2018:50:1178-82.

46 Ganz T. Hepcidin and the global burden of iron deficiency. Clin Chem 2015;61:577-8.

47 Lang AT, Johnson S, Sturm M, et al. Iron deficiency without anemia: a common yet under-recognized diagnosis in young women with heavy menstrual bleeding. Blood 2014; $124: 3510$.

48 Ioannou GN, Spector J, Scott K, et al. Prospective evaluation of a clinical guideline for the diagnosis and management of iron deficiency anemia. Am J Med 2002;113:281-7

49 Radia D, Momoh I, Dillon R, et al. Anemia management: development of a rapidaccess anemia and intravenous iron service. Risk Manag Healthc Policy 2013;6:13-22.

50 Surgenor SL, Kirkham S, Parry SD, et al. The development of a nurse-led iron deficiency anaemia service in a district general Hospital. Frontline Gastroenterol 2014;5:219-23.

51 Townsend SA, Cheung D, Horne E, et al. A 5-year follow-up of study patients with asymptomatic iron-deficiency anemia using a nurse-led pathway. Gastroenterol Nurs 2016:39:466-71

52 De Falco L, Sanchez M, Silvestri L, et al. Iron refractory iron deficiency anemia. Haematologica 2013;98:845-53.
53 Tran-Duy A, Connell NJ, Vanmolkot FH, et al. Use of proton pump inhibitors and risk of iron deficiency: a population-based case-control study. J Intern Med 2019;285:205-14.

54 Coates A, Mountjoy M, Burr J. Incidence of iron deficiency and iron deficient anemia in elite runners and triathletes. Clin J Sport Med 2017;27:493-8.

55 Mahadev S, Laszkowska M, Sundström J, et al. Prevalence of celiac disease in patients with iron deficiency Anemia-A systematic review with meta-analysis. Gastroenterology 2018;155:374-82

56 Stroud C, Almilaji 0, Nicholas D, et al. Evolving patterns in the presentation of coeliac disease over the last 25 years. Frontline Gastroenterol 2020;11:98-103

57 Nayagam J, Ha S, Barreto L. PTU-120 iron deficiency anaemia in renal cell carcinoma. Gut2018;67:A250-2.

58 Pengelly S, Fabricius M, McMenamin D, et al. Attendance at iron deficiency anaemia clinic: audit of outcomes 5 years on. Colorectal Dis 2013;15:423-7.

59 Atkin W, Dadswell E, Wooldrage K, et al. Computed tomographic colonography versus colonoscopy for investigation of patients with symptoms suggestive of colorectal cancer (SIGGAR): a multicentre randomised trial. Lancet 2013;381:1194-202.

60 Halligan S, Altman DG, Taylor SA, et al. Ct colonography in the detection of colorectal polyps and cancer: systematic review, meta-analysis, and proposed minimum data set for study level reporting. Radiology 2005;237:893-904

61 Kaye PV, Garsed K, Ragunath K, et al. The clinical utility and diagnostic yield of routine gastric biopsies in the investigation of iron deficiency anemia: a case-control study. Am J Gastroenterol 2008:103:2883-9.

62 Hudak L, Jaraisy A, Haj S, et al. An updated systematic review and meta-analysis on the association between Helicobacter pylori infection and iron deficiency anemia. Helicobacter 2017;22. doi:10.1111/hel.12330. [Epub ahead of print: 13 07 2016].

63 Almilaji O, Snook JA, Thomas P. The IDIOM APP, 2020. Available: https://www. predict-gi-risk-in-ida.com [Accessed 16 Feb 2021].

64 Chapman C, Bunce J, Oliver S, et al. Service evaluation of faecal immunochemical testing and anaemia for risk stratification in the 2-week-wait pathway for colorectal cancer. BJS Open 2019;3:395-402.

65 Mowat C, Digby J, Strachan JA, et al. Impact of introducing a faecal immunochemical test (fit) for haemoglobin into primary care on the outcome of patients with new bowel symptoms: a prospective cohort study. BMJ Open Gastroenterol 2019;6:e000293.

66 Nicholson BD, James T, Paddon M, et al. Faecal immunochemical testing for adults with symptoms of colorectal cancer attending English primary care: a retrospective cohort study of 14487 consecutive test requests. Aliment Pharmacol Ther 2020;52:1031-41.

67 D'Souza N, Georgiou Delisle T, Chen M, et al. Faecal immunochemical test is superior to symptoms in predicting pathology in patients with suspected colorectal cancer symptoms referred on a 2WW pathway: a diagnostic accuracy study. Gut 2021;70:1130-8.

68 Laszlo HE, Seward E, Ayling RM. Quantitative faecal immunochemical test for patients with 'high risk' bowel symptoms: a prospective cohort study.

69 Cunin L, Khan AA, Ibrahim M, et al. Fit negative cancers: a right-sided problem? implications for screening and whether iron deficiency anaemia has a role to play. Surgeon 2021;19:27-32.

70 Lee MW, Pourmorady JS, Laine L. Use of fecal occult blood testing as a diagnostic tool for clinical indications: a systematic review and meta-analysis. Am J Gastroenterol 2020;115:662-70.

71 Hill ID. What are the sensitivity and specificity of serologic tests for celiac disease? Do sensitivity and specificity vary in different populations? Gastroenterology 2005; 128:S25-32.

72 Hopper AD, Hadjivassiliou M, Hurlstone DP, et al. What is the role of serologic testing in celiac disease? A prospective, biopsy-confirmed study with economic analysis. Clin Gastroenterol Hepatol 2008:6:314-20.

73 Hopper AD, Cross SS, Hurlstone DP, et al. Pre-endoscopy serological testing for coeliac disease: evaluation of a clinical decision tool. BMJ 2007:334:729.

74 Werkstetter KJ, Korponay-Szabó IR, Popp A, et al. Accuracy in Diagnosis of Celiac Disease Without Biopsies in Clinical Practice. Gastroenterology 2017;153:924-35.

75 Volta U, Caio G, Boschetti E, et al. Seronegative celiac disease: shedding light on an obscure clinical entity. Dig Liver Dis 2016;48:1018-22.

76 Schiepatti A, Biagi F, Fraternale G, et al. Short article: mortality and differential diagnoses of villous atrophy without coeliac antibodies. Eur J Gastroenterol Hepatol 2017;29:572-6

77 Salmi TT, Collin P, Korponay-Szabó IR, et al. Endomysial antibody-negative coeliac disease: clinical characteristics and intestinal autoantibody deposits. Gut 2006:55:1746-53.

78 Gasbarrini G, Ciccocioppo R, De Vitis I, et al. Coeliac disease in the elderly. Gerontology 2001;47:306-10.

79 Tortora R, Zingone F, Rispo A, et al. Coeliac disease in the elderly in a tertiary centre. Scand J Gastroenterol 2016:51:1179-83.

80 Hankey GL, Holmes GK. Coeliac disease in the elderly. Gut 1994;35:65-7.

81 Freeman H. Clinical spectrum of biopsy-defined coeliac disease in the elderly. Can J Gastroenterol 1995;9:42-6 
82 West J, Logan RFA, Hill PG, et al. Seroprevalence, correlates, and characteristics of undetected coeliac disease in England. Gut 2003;52:960-5.

83 Godfrey JD, Brantner TL, Brinjikji W, et al. Morbidity and mortality among older individuals with undiagnosed celiac disease. Gastroenterology 2010;139:763-9.

84 Freeman HJ. Adult celiac disease and its malignant complications. Gut Liver 2009;3:237-46.

85 Sahay R, Scott BB. Iron deficiency anaemia--how far to investigate? Gut 1993;34:1427-8.

86 Soon A, Cohen BL, Groessl EJ, et al. Long-Term outcomes and prognostic factors for patients with endoscopy-negative iron deficiency. Dig Dis Sci 2013;58:488-95.

87 Clere-Jehl R, Sauleau E, Ciuca S, et al. Outcome of endoscopy-negative iron deficiency anemia in patients above 65: a longitudinal multicenter cohort. Medicine 2016;95:e5339.

88 McLoughlin MT, Tham TCK. Long-Term follow-up of patients with iron deficiency anaemia after a negative gastrointestinal evaluation. Eur J Gastroenterol Hepatol 2009;21:872-6.

89 Sidhu PS, McAlindon ME, Drew K, et al. The utility of capsule endoscopy in patients under 50 years of age with recurrent iron deficiency anaemia: is the juice worth the squeeze? Gastroenterol Res Pract 2015:2015:1-5.

90 Pennazio M, Spada C, Eliakim R, et al. Small-Bowel capsule endoscopy and device-assisted enteroscopy for diagnosis and treatment of small-bowel disorders: European Society of gastrointestinal endoscopy (ESGE) clinical guideline. Endoscopy 2015:47:352-76

91 Marmo R, Rotondano G, Piscopo R, et al. Meta-analysis: capsule enteroscopy vs. conventional modalities in diagnosis of small bowel diseases. Aliment Pharmacol Ther 2005;22:595-604.

92 Triester SL, Leighton JA, Leontiadis Gl, et al. A meta-analysis of the yield of capsule endoscopy compared to other diagnostic modalities in patients with obscure gastrointestinal bleeding. Am J Gastroenterol 2005;100:2407-18.

93 Koulaouzidis A, Rondonotti E, Giannakou A, et al. Diagnostic yield of small-bowel capsule endoscopy in patients with iron-deficiency anemia: a systematic review. Gastrointest Endosc 2012;76:983-92.

94 Carey EJ, Leighton JA, Heigh RI, et al. A single-center experience of 260 consecutive patients undergoing capsule endoscopy for obscure gastrointestinal bleeding. Am J Gastroenterol 2007;102:89-95.

95 Shahidi NC, Ou G, Svarta S, et al. Factors associated with positive findings from capsule endoscopy in patients with obscure gastrointestinal bleeding. Clin Gastroenterol Hepatol 2012;10:1381-5.

96 Xavier S, Magalhães J, Rosa B, et al. Impact of small bowel capsule endoscopy in iron deficiency anemia: influence of PATIENT'SAGE on diagnostic yield. Arq Gastroenterol 2018;55:242-6.

97 Olano C, Pazos X, Avendaño K, et al. Diagnostic yield and predictive factors of findings in small-bowel capsule endoscopy in the setting of iron-deficiency anemia. Endosc Int Open 2018;6:E688-93.

98 Girelli CM, Soncini M, Rondonotti E. Implications of small-bowel transit time in the detection rate of capsule endoscopy: a multivariable multicenter study of patients with obscure gastrointestinal bleeding. World J Gastroenterol 2017;23:697-702.

99 Koffas A, Laskaratos F-M, Epstein 0. Non-Small bowel lesion detection at small bowel capsule endoscopy: a comprehensive literature review. World J Clin Cases 2018:6:901-7.

100 Hoedemaker RA, Westerhof J, Weersma RK, et al. Non-small-bowel abnormalities identified during small bowel capsule endoscopy. World J Gastroenterol 2014;20:4025-9.

101 Vlachogiannakos J, Papaxoinis K, Viazis N, et al. Bleeding lesions within reach of conventional endoscopy in capsule endoscopy examinations for obscure gastrointestinal bleeding: is repeating endoscopy economically feasible? Dig Dis SCi 2011:56:1763-8

102 Gilbert D, O'Malley S, Selby W. Are repeat upper gastrointestinal endoscopy and colonoscopy necessary within six months of capsule endoscopy in patients with obscure gastrointestinal bleeding? J Gastroenterol Hepatol 2008;23:1806-9.

103 Koulaouzidis A, Yung DE, Lam JHP, et al. The use of small-bowel capsule endoscopy in iron-deficiency anemia alone; be aware of the young anemic patient. Scand J Gastroenterol 2012:47:1094-100.

104 Yung DE, Rondonotti E, Giannakou A, et al. Capsule endoscopy in young patients with iron deficiency anaemia and negative bidirectional gastrointestinal endoscopy. United European Gastroenterol J 2017;5:974-81.

105 Yung DE, Koulaouzidis A, Avni T, et al. Clinical outcomes of negative small-bowel capsule endoscopy for small-bowel bleeding: a systematic review and meta-analysis. Gastrointest Endosc 2017;85:305-17.

106 Hakim FA, Alexander JA, Huprich JE, et al. CT-enterography may identify small bowel tumors not detected by capsule endoscopy: eight years experience at Mayo clinic Rochester. Dig Dis Sci 2011;56:2914-9.

107 Robertson AR, Yung DE, Douglas S, et al. Repeat capsule endoscopy in suspected gastrointestinal bleeding. Scand J Gastroenterol 2019:54:656-61.

108 Park JJ, Cheon JH, Kim HM, et al. Negative capsule endoscopy without subsequent enteroscopy does not predict lower long-term rebleeding rates in patients with obscure Gi bleeding. Gastrointest Endosc 2010;71:990-7.
109 Teshima CW, Kuipers EJ, van Zanten SV, et al. Double balloon enteroscopy and capsule endoscopy for obscure gastrointestinal bleeding: an updated meta-analysis. J Gastroenterol Hepatol 2011;26:796-801.

110 Rahmi G, Samaha E, Vahedi K, et al. Long-Term follow-up of patients undergoing capsule and double-balloon enteroscopy for identification and treatment of small-bowel vascular lesions: a prospective, multicenter study. Endoscopy 2014:46:591-7

111 Samaha E, Rahmi G, Landi B, et al. Long-Term outcome of patients treated with double balloon enteroscopy for small bowel vascular lesions. Am J Gastroentero 2012;107:240-6.

112 Romagnuolo J, Brock AS, Ranney N. Is endoscopic therapy effective for Angioectasia in obscure gastrointestinal bleeding?: a systematic review of the literature. J Clin Gastroenterol 2015:49:823-30.

113 He B, Yang J, Xiao J, et al. Accuracy of computed tomographic Enterography for obscure gastrointestinal bleeding: a diagnostic meta-analysis. Acad Radiol 2018;25:196-201.

114 Wang Z, Chen J-qiang, Liu J-lu, et al. Ct enterography in obscure gastrointestinal bleeding: a systematic review and meta-analysis. J Med Imaging Radiat Oncol 2013:57:263-73

115 Huprich JE, Fletcher JG, Fidler JL, et al. Prospective blinded comparison of wireless capsule endoscopy and multiphase CT enterography in obscure gastrointestinal bleeding. Radiology 2011;260:744-51.

116 Evstatiev R, Marteau P, Iqbal T, et al. FERGIcor, a randomized controlled trial on ferric carboxymaltose for iron deficiency anemia in inflammatory bowel disease. Gastroenterology 2011;141:846-53

117 Van Wyck DB, Mangione A, Morrison J, et al. Large-Dose intravenous ferric carboxymaltose injection for iron deficiency anemia in heavy uterine bleeding: a randomized, controlled trial. Transfusion 2009:49:2719-28.

118 Zhang S, Zhang F, Du M, et al. Efficacy and safety of iron supplementation in patients with heart failure and iron deficiency: a meta-analysis. $\mathrm{Br} J \mathrm{Nutr}$ 2019:121:841-8

119 Gurusamy KS, Nagendran M, Broadhurst JF, et al. Iron therapy in anaemic adults without chronic kidney disease. Cochrane Database Syst Rev 2014:CD010640.

120 Kaundal R, Bhatia P, Jain A, et al. Randomized controlled trial of twice-daily versus alternate-day oral iron therapy in the treatment of iron-deficiency anemia. Ann Hematol 2020;99:57-63.

121 Baird IM, Walters RL, Sutton DR. Absorption of slow-release iron and effects of ascorbic acid in normal subjects and after partial gastrectomy. Br Med J 1974:4:505-8.

122 Ekenved G. Absorption from different types of iron tablets - correlation between serum iron increase in total absorption of iron. Scand J Haematol Supp/ 1976;28:51-63.

123 Tolkien Z, Stecher L, Mander AP, et al. Ferrous sulfate supplementation causes significant gastrointestinal side-effects in adults: a systematic review and metaanalysis. PLoS One 2015;10:e0117383.

124 Cook JD, Reddy MB. Efficacy of Weekly compared with daily iron supplementation. Am J Clin Nutr 1995;62:117-20.

125 Ahmad Fuzi SF, Koller D, Bruggraber S, et al. A 1-h time interval between a meal containing iron and consumption of tea attenuates the inhibitory effects on iron absorption: a controlled trial in a cohort of healthy UK women using a stable iron isotope. Am J Clin Nutr 2017;106:1413-21.

126 Li N, Zhao G, Wu W, et al. The efficacy and safety of vitamin C for iron supplementation in adult patients with iron deficiency anemia: a randomized clinical trial. JAMA Netw Open 2020;3:e2023644.

127 Vyoral D, Jiri P. Therapeutic potential of hepcidin - the master regulator of iron metabolism. Pharmacol Res 2017;115:242-54.

128 Pasricha S-R, McHugh K, Drakesmith H. Regulation of hepcidin by erythropoiesis: the story so far. Annu Rev Nutr 2016;36:417-34.

129 Frazer DM, Wilkins SJ, Becker EM, et al. A rapid decrease in the expression of DMT1 and Dcytb but not Ireg1 or hephaestin explains the mucosal block phenomenon of iron absorption. Gut 2003:52:340-6.

130 Valberg LS. Plasma ferritin concentrations: their clinical significance and relevance to patient care. Can Med Assoc J 1980;122:1240-8

131 Moretti D, Goede JS, Zeder C, et al. Oral iron supplements increase hepcidin and decrease iron absorption from daily or twice-daily doses in iron-depleted young women. Blood 2015:126:1981-9.

132 Stoffel NU, Cercamondi Cl, Brittenham G, et al. Iron absorption from oral iron supplements given on consecutive versus alternate days and as single morning doses versus twice-daily split dosing in iron-depleted women: two open-label, randomised controlled trials. Lancet Haematol 2017:4:e524-33.

133 Rimon E, Kagansky N, Kagansky M, et al. Are we giving too much iron? Low-dose iron therapy is effective in octogenarians. Am J Med 2005;118:1142-7.

134 Stoffel NU, Zeder C, Brittenham GM, et al. Iron absorption from supplements is greater with alternate day than with consecutive day dosing in iron-deficient anemic women. Haematologica 2020;105:1232-9.

135 Kianfar H, Kimiagar M, Ghaffarpour M. Effect of daily and intermittent iron supplementation on iron status of high school girls. Int J Vitam Nutr Res 2000;70:172-7 
136 Fernández-Gaxiola AC, De-Regil LM. Intermittent iron supplementation for reducing anaemia and its associated impairments in adolescent and adult menstruating women. Cochrane Database Syst Rev 2019;1:CD009218.

137 Peña-Rosas JP, De-Regil LM, Gomez Malave H, et al. Intermittent oral iron supplementation during pregnancy. Cochrane Database Syst Rev 2015:CD009997.

138 Gasche C, Ahmad T, Tulassay Z, et al. Ferric maltol is effective in correcting iron deficiency anemia in patients with inflammatory bowel disease: results from a phase-3 clinical trial program. Inflamm Bowel Dis 2015;21:579-88.

139 Schmidt C, Ahmad T, Tulassay Z, et al. Ferric maltol therapy for iron deficiency anaemia in patients with inflammatory bowel disease: long-term extension data from a phase 3 study. Aliment Pharmacol Ther 2016;44:259-70.

140 Cummings JF, Fraser A, Stansfield C, et al. Ferric maltol real-world effectiveness study in hospital practice (fresh): clinical characteristics and outcomes of patients with inflammatory bowel disease receiving ferric maltol for iron-deficiency anaemia in the UK. BMJ Open Gastroenterol 2021;8:e000530.

141 NICE. NICE Guideline NG24 - Chronic kidney disease: managing anaemia. London: NICE, 2015. https://www.nice.org.uk/guidance/ng8/resources/chronic-kidneydisease-managing-anaemia-pdf-51046844101

142 Okam MM, Koch TA, Tran M-H. Iron deficiency anemia treatment response to oral iron therapy: a pooled analysis of five randomized controlled trials. Haematologica 2016:101:e6-7.

143 Bentley DP, Jacobs A. Accumulation of storage iron in patients treated for irondeficiency anaemia. Br Med J 1975;2:64-6.

144 Kulnigg S, Stoinov S, Simanenkov V, et al. A novel intravenous iron formulation for treatment of anemia in inflammatory bowel disease: the ferric carboxymaltose (FERINJECT) randomized controlled trial. Am J Gastroenterol 2008;103:1182-92.

145 Reinisch W, Staun M, Tandon RK, et al. A randomized, open-label, noninferiority study of intravenous iron isomaltoside 1,000 (Monofer) compared with oral iron for treatment of anemia in IBD (proceed). Am J Gastroenterol 2013; 108:1877-88.

146 Darwish AM, Khalifa EE, Rashad E, et al. Total dose iron dextran infusion versus oral iron for treating iron deficiency anemia in pregnant women: a randomized controlled trial. J Matern Fetal Neonatal Med 2019;32:398-403.

147 Bager P, Dahlerup JF. Randomised clinical trial: oral vs. intravenous iron after upper gastrointestinal haemorrhage--a placebo-controlled study. Aliment Pharmacol Ther 2014;39:176-87.

148 Lindgren S, Wikman O, Befrits $\mathrm{R}$, et al. Intravenous iron sucrose is superior to oral iron sulphate for correcting anaemia and restoring iron stores in IBD patients: a randomized, controlled, evaluator-blind, multicentre study. Scand I Gastroenterol 2009;44:838-45.

149 Bisbe E, Moltó L, Arroyo R, et al. Randomized trial comparing ferric carboxymaltose vs oral ferrous glycine sulphate for postoperative anaemia after total knee arthroplasty. Br J Anaesth 2014:113:402-9.

150 Ganz T, Nemeth E. Hepcidin and iron homeostasis. Biochim Biophys Acta 2012;1823:1434-43.

151 Ganzoni AM. [Intravenous iron-dextran: therapeutic and experimental possibilities]. Schweiz Med Wochenschr 1970;100:301-3.

152 Avni T, Bieber A, Grossman A, et al. The safety of intravenous iron preparations: systematic review and meta-analysis. Mayo Clin Proc 2015;90:12-23.

153 Derman $\mathrm{R}$, Roman E, Modiano MR, et al. A randomized trial of iron isomaltoside versus iron sucrose in patients with iron deficiency anemia. Am J Hematol 2017;92:286-91.

154 Auerbach M, Henry D, Derman RJ, et al. A prospective, multi-center, randomized comparison of iron isomaltoside 1000 versus iron sucrose in patients with iron deficiency anemia; the FERWON-IDA trial. Am J Hematol 2019;94:1007-14.

155 Pratt JJ, Khan KS. Non-anaemic iron deficiency - a disease looking for recognition of diagnosis: a systematic review. Eur J Haematol 2016;96:618-28.

156 Krayenbuehl P-A, Battegay E, Breymann C, et al. Intravenous iron for the treatment of fatigue in nonanemic, premenopausal women with low serum ferritin concentration. Blood 2011;118:3222-7.

157 Pittori C, Buser A, Gasser UE, et al. A pilot iron substitution programme in female blood donors with iron deficiency without anaemia. Vox Sang 2011;100:303-11.

158 Favrat B, Balck K, Breymann C, et al. Evaluation of a single dose of ferric carboxymaltose in fatigued, iron-deficient women--PREFER a randomized, placebocontrolled study. PLoS One 2014;9:e94217.

159 Verdon F, Burnand B, Stubi C-LF, et al. Iron supplementation for unexplained fatigue in non-anaemic women: double blind randomised placebo controlled trial. BMJ 2003:326:1124.

160 Houston BL, Hurrie D, Graham J, et al. Efficacy of iron supplementation on fatigue and physical capacity in non-anaemic iron-deficient adults: a systematic review of randomised controlled trials. BMJ Open 2018:8:e019240.

161 Dickey S, Rockey DC. The natural history of iron deficiency anemia. Am J Med Sci 2019;358:357-62.

162 Cancelo-Hidalgo MJ, Castelo-Branco C, Palacios S, et al. Tolerability of different oral iron supplements: a systematic review. Curr Med Res Opin 2013;29:291-303.

163 Hallberg L, Ryttinger L, Sölvell L. Side-Effects of oral iron therapy. A doubleblind study of different iron compounds in tablet form. Acta Med Scand Supp/ 1966;459:3-10.
164 Bonovas S, Fiorino G, Allocca M, et al. Intravenous versus oral iron for the treatment of anemia in inflammatory bowel disease: a systematic review and meta-analysis of randomized controlled trials. Medicine 2016;95:e2308.

165 Onken JE, Bregman DB, Harrington RA, et al. A multicenter, randomized, active-controlled study to investigate the efficacy and safety of intravenous ferric carboxymaltose in patients with iron deficiency anemia. Transfusion 2014;54:306-15

166 Varner RE, Ireland CC, Summitt RL, et al. Medicine or surgery (MS): a randomized clinical trial comparing hysterectomy and medical treatment in premenopausal women with abnormal uterine bleeding. Control Clin Trials 2004;25:104-18.

167 Carlson KJ, Miller BA, Fowler FJ. The Maine women's health study: Il. outcomes of nonsurgical management of leiomyomas, abnormal bleeding, and chronic pelvic pain. Obstet Gynecol 1994;83:566-72.

168 DeLoughery TG. Safety of oral and intravenous iron. Acta Haematol 2019;142:8-12

169 Richards T, Baikady RR, Clevenger B, et al. Preoperative intravenous iron to treat anaemia before major abdominal surgery (PREVENTT): a randomised, double-blind, controlled trial. The Lancet 2020;396:1353-61.

170 Bellos I, Frountzas M, Pergialiotis V. Comparative risk of hypophosphatemia following the administration of intravenous iron formulations: a network meta-analysis. Transfus Med Rev 2020;34:188-94.

171 Detlie TE, Lindstrøm JC, Jahnsen ME, et al. Incidence of hypophosphatemia in patients with inflammatory bowel disease treated with ferric carboxymaltose or iron isomaltoside. Aliment Pharmacol Ther 2019;50:397-406.

172 Medicines and Healthcare Regulatory Agency. Ferric carboxymaltose (Ferinject) : risk of symptomatic hypophosphataemia leading to osteomalacia and fractures. London: Gov.UK, 2020. https://www.gov.uk/drug-safety-update/ferric-carboxymaltoseferinject-risk-of-symptomatic-hypophosphataemia-leading-to-osteomalacia-andfractures

173 World Health Organisation. The prevalence of anaemia in women: a Tabulation of available information. 2nd edn. Geneva:WHO, 1992. https://apps.who.int/ iris/bitstream/handle/10665/58994/WHO_MCH_MSM_92.2.pdf?sequence=18 isAllowed $=\mathrm{y}$

174 Looker AC, Dallman PR, Carroll MD, et al. Prevalence of iron deficiency in the United States. JAMA 1997;277:973-6.

175 Allen LH. Pregnancy and iron deficiency: unresolved issues. Nutr Rev 1997:55:91-101

176 McKenna DM, Dockeray CJ, McCann SR. Iron deficiency in pre-menopausal females. Ir Med J 1989;82:69-70.

177 Bini EJ, Micale PL, Weinshel EH. Evaluation of the gastrointestinal tract in premenopausal women with iron deficiency anemia. Am J Med 1998;105:281-6.

178 Kepczyk T, Cremins JE, Long BD, et al. A prospective, multidisciplinary evaluation of premenopausal women with iron-deficiency anemia. Am J Gastroenterol 1999:94:109-15.

179 Nahon S, Lahmek P, Lesgourgues B, et al. Predictive factors of Gi lesions in 241 women with iron deficiency anemia. Am J Gastroenterol 2002;97:590-3.

180 Ioannou GN, Rockey DC, Bryson CL, et al. Iron deficiency and gastrointestinal malignancy: a population-based cohort study. Am J Med 2002;113:276-80.

181 Luman W, Ng KL. Audit of investigations in patients with iron deficiency anaemia. Singapore Med J 2003;44:504-10.

182 Annibale B, Lahner E, Chistolini A, et al. Endoscopic evaluation of the upper gastrointestinal tract is worthwhile in premenopausal women with iron-deficiency anaemia irrespective of menstrual flow. Scand J Gastroenterol 2003;38:239-45

183 Bini EJ, Micale PL, Weinshel EH. Gastrointestinal endoscopy in premenopausal women with iron deficiency anemia: determination of the best diagnostic approach. Am J Gastroenterol 1999:94:1715.

184 Cairns SR, Scholefield JH, Steele RJ, et al. Guidelines for colorectal cancer screening and surveillance in moderate and high risk groups (update from 2002). Gut 2010;59:666-89

185 Siddiqui U, Denise Proctor D. Flexible sigmoidoscopy and colonoscopy during pregnancy. Gastrointest Endosc Clin N Am 2006;16:59-69.

186 Carter D, Levi G, Tzur D, et al. Prevalence and predictive factors for gastrointestinal pathology in young men evaluated for iron deficiency anemia. Dig Dis Sci 2013:58:1299-305.

187 Fairweather-Tait SJ, Wawer AA, Gillings R, et al. Iron status in the elderly. Mech Ageing Dev 2014;136-137:22-8.

188 Wawer AA, Jennings A, Fairweather-Tait SJ. Iron status in the elderly: a review of recent evidence. Mech Ageing Dev 2018;175:55-73.

189 Busti F, Campostrini N, Martinelli N, et al. Iron deficiency in the elderly population, revisited in the hepcidin era. Front Pharmacol 2014;5:83.

190 Joosten E. Iron deficiency anemia in older adults: a review. Geriatr Gerontol Int 2018;18:373-9.

191 Cappellini MD, Comin-Colet J, de Francisco A, et al. Iron deficiency across chronic inflammatory conditions: international expert opinion on definition, diagnosis, and management. Am J Hematol 2017:92:1068-78.

192 Padhi S, Glen J, Pordes BAJ, et al. Management of anaemia in chronic kidney disease: summary of updated NICE guidance. BMJ 2015;350:h2258.

193 Mikhail A, Brown C, Williams JA, et al. Renal association clinical practice guideline on anaemia of chronic kidney disease. BMC Nephrol 2017;18:345 
194 Gafter-Gvili A, Schechter A, Rozen-Zvi B. Iron deficiency anemia in chronic kidney disease. Acta Haematol 2019;142:44-50.

195 von Haehling S, Ebner N, Evertz R, et al. Iron deficiency in heart failure: an overview. JACC Heart Fail 2019;7:36-46.

196 Jankowska EA, Tkaczyszyn M, Suchocki T, et al. Effects of intravenous iron therapy in iron-deficient patients with systolic heart failure: a meta-analysis of randomized controlled trials. Eur J Heart Fail 2016;18:786-95.

197 Anker SD, Kirwan B-A, van Veldhuisen DJ, et al. Effects of ferric carboxymaltose on hospitalisations and mortality rates in iron-deficient heart failure patients: an individual patient data meta-analysis. Eur J Heart Fail 2018;20:125-33.

198 McDonagh T, Damy T, Doehner W, et al. Screening, diagnosis and treatment of iron deficiency in chronic heart failure: putting the 2016 European Society of cardiology heart failure guidelines into clinical practice. Eur J Heart Fail 2018;20:1664-72.

199 Lamb CA, Kennedy NA, Raine T, et al. British Society of gastroenterology consensus guidelines on the management of inflammatory bowel disease in adults. Gut 2019;68:s1-106.

200 Dignass AU, Gasche C, Bettenworth D, et al. European consensus on the diagnosis and management of iron deficiency and anaemia in inflammatory bowel diseases. J Crohns Colitis 2015:9:211-22.

201 Aksan A, Wohlrath M, Iqbal TH, et al. Inflammation, but not the underlying disease or its location, predicts oral iron absorption capacity in patients with inflammatory bowel disease. J Crohns Colitis 2020;14:316-22.

202 Gowanlock Z, Lezhanska A, Conroy M, et al. Iron deficiency following bariatric surgery: a retrospective cohort study. Blood Adv 2020:4:3639-47.

203 Ruz M, Carrasco F, Rojas P, et al. Heme- and nonheme-iron absorption and iron status $12 \mathrm{Mo}$ after sleeve gastrectomy and Roux-en-Y gastric bypass in morbidly obese women. Am J Clin Nutr 2012;96:810-7.

204 Weng T-C, Chang C-H, Dong Y-H, et al. Anaemia and related nutrient deficiencies after Roux-en-Y gastric bypass surgery: a systematic review and meta-analysis. BMJ Open 2015;5:e006964.

205 Engebretsen KV, Blom-Høgestøl IK, Hewitt S, et al. Anemia following Roux-en-Y gastric bypass for morbid obesity; a 5-year follow-up study. Scand J Gastroenterol 2018:53:917-22.

206 McCracken E, Wood GC, Prichard W, et al. Severe anemia after Roux-en-Y gastric bypass: a cause for concern. Surg Obes Relat Dis 2018;14:902-9.
207 Ferraz Álvaro Antonio Bandeira, Carvalho MRC, Siqueira LT, et al. Micronutrient deficiencies following bariatric surgery: a comparative analysis between sleeve gastrectomy and RouX-en-Y gastric bypass. Rev Col Bras Cir 2018;45:e2016.

208 Bini EJ, Unger JS, Weinshel EH. Outcomes of endoscopy in patients with iron deficiency anemia after Billroth II partial gastrectomy. J Clin Gastroenterol 2002:34:421-6.

209 Lundegårdh G, Adami HO, Helmick C, et al. Stomach cancer after partial gastrectomy for benign ulcer disease. N Eng/ J Med 1988:319:195-200.

210 Defilipp Z, Lister J, Gagné D, et al. Intravenous iron replacement for persistent iron deficiency anemia after Roux-en-Y gastric bypass. Surg Obes Relat Dis 2013:9:129-32.

211 Kotkiewicz A, Donaldson K, Dye C, et al. Anemia and the need for intravenous iron infusion after Roux-en-Y gastric bypass. Clin Med Insights Blood Disord 2015;8:CMBD.S21825-17.

212 Mankodi S, Hayee BH, O'Donohue J, et al. Anaemia investigation in practice: inappropriate, cost inefficient with a risk of missing gastrointestinal cancer. can we improve? Clin Med 2010:10:115-8.

213 Shaw AG, Simpson J, Tierney G, et al. Referral of patients with iron deficiency anaemia under the lower gastrointestinal two-week wait rule. Colorect Dis 2008; 10:294-7.

214 Svenson N, Desborough R, Fletcher A. Re-Evaluation and collaboration of laboratory testing pathway for iron deficiency anaemia. Br J Haematol 2019;185:62.

215 Pendry K. Managing anaemia in the outpatient setting. ISBT Sci Ser 2016:11:76-84.

216 Shandro BM, Basuroy R, Gamble L, et al. PTH-131 First Year Results from a Virtual Iron Deficiency Anaemia Service at a District General Hospital. Gut 2013;62:A264.2-5.

217 Brookes MJ, Farr A, Phillips CJ, et al. Management of iron deficiency anaemia in secondary care across England between 2012 and 2018: a real-world analysis of hospital episode statistics. Frontline Gastroenterol;19. doi:10.1136/ flgastro-2020-101506. [Epub ahead of print: 26 Oct 2020].

218 Canadian Agency for Drugs and Technologies in Health. Oral iron for anemia: a review of the clinical effectiveness, cost-effectiveness and guidelines. Available: https://cadth.ca/oral-iron-anemia-review-clinical-effectiveness-cost-effectivenessand-guidelines [Accessed 16 Feb 2021]. 